\title{
Transcript profiling of cytokinin action in Arabidopsis roots and shoots discovers largely similar but also organ-specific responses
}

Wolfram G Brenner and Thomas Schmülling*

\begin{abstract}
Background: The plant hormone cytokinin regulates growth and development of roots and shoots in opposite ways. In shoots it is a positive growth regulator whereas it inhibits growth in roots. It may be assumed that organ-specific regulation of gene expression is involved in these differential activities, but little is known about it. To get more insight into the transcriptional events triggered by cytokinin in roots and shoots, we studied genome-wide gene expression in cytokinin-treated and cytokinin-deficient roots and shoots.

Results: It was found by principal component analysis of the transcriptomic data that the immediate-early response to a cytokinin stimulus differs from the later response, and that the transcriptome of cytokinin-deficient plants is different from both the early and the late cytokinin induction response. A higher cytokinin status in the roots activated the expression of numerous genes normally expressed predominantly in the shoot, while a lower cytokinin status in the shoot reduced the expression of genes normally more active in the shoot to a more root-like level. This shift predominantly affected nuclear genes encoding plastid proteins. An organ-specific regulation was assigned to a number of genes previously known to react to a cytokinin signal, including root-specificity for the cytokinin hydroxylase gene CYP735A2 and shoot specificity for the cell cycle regulator gene $C D K A ; 1$. Numerous cytokinin-regulated genes were newly discovered or confirmed, including the meristem regulator genes SHEPHERD and CLAVATA1, auxin-related genes (IAA7, IAA13, AXR1, PIN2, PID), several genes involved in brassinosteroid (CYP710A1, CYP710A2, DIM/DWF) and flavonol (MYB12, CHS, FLS1) synthesis, various transporter genes (e.g. HKT1), numerous members of the AP2/ERF transcription factor gene family, genes involved in light signalling (PhyA, COP1, SPA1), and more than 80 ribosomal genes. However, contrasting with the fundamental difference of the growth response of roots and shoots to the hormone, the vast majority of the cytokinin-regulated transcriptome showed similar response patterns in roots and shoots.

Conclusions: The shift of the root and shoot transcriptomes towards the respective other organ depending on the cytokinin status indicated that the hormone determines part of the organ-specific transcriptome pattern independent of morphological organ identity. Numerous novel cytokinin-regulated genes were discovered which had escaped earlier discovery, most probably due to unspecific sampling. These offer novel insights into the diverse activities of cytokinin, including crosstalk with other hormones and different environmental cues, identify the AP2/ERF class of transcriptions factors as particularly cytokinin sensitive, and also suggest translational control of cytokinin-induced changes.
\end{abstract}

\footnotetext{
* Correspondence: tschmue@zedat.fu-berlin.de

Institute of Biology/Applied Genetics, Dahlem Centre of Plant Sciences (DCPS), Freie Universität Berlin, Albrecht-Thaer-Weg 6, D-14195, Berlin, Germany
} 


\section{Background}

Cytokinin is a plant hormone regulating numerous developmental and physiological activities [1,2]. Many molecular details of cytokinin metabolism and signal transduction have been discovered during recent years. It is known that cytokinin acts locally as well as over a distance, that it is synthesized and degraded in different root and shoot tissues and that its signal is transduced through a complex two-component system. In Arabidopsis thaliana, three membrane-located sensor histidine kinases - AHK2, AHK3 and CRE1/AHK4 - perceive the signal and transmit it through a phosphorelay via phosphotransmitter proteins (AHP) to the nucleus where B-type response regulators (ARR), a class of transcription factors, become activated and induce the transcription of numerous target genes [3-5]. It has been shown that the B-type ARRs are involved in mediating most if not all of the transcriptional responses to cytokinin [6-8]. Genome-wide analyses of the Arabidopsis transcriptome have identified many genes that show a rapid up- or downregulation of their steady-state mRNA level in response to cytokinin [6,7,9-18], reviewed in [19]. Among these are numerous genes encoding transcription factors suggesting that transcriptional cascades operate downstream of cytokinin and are involved in realizing the biological output reactions. Indeed, functional studies have confirmed that beside the B-type ARRs, other factors are involved in mediating the transcriptional response to cytokinin. These include a subgroup of the ERF/AP2 transcription factor family named CYTOKININ RESPONSE FACTOR (CRF) [16], members of the GeBP transcription factor family [20] and GATA22 [21,22].

An interesting feature of cytokinin is its opposite activity in regulating growth of roots and shoots. Cytokinin is a negative regulator of root growth and branching. Plants with a reduced cytokinin status - generated either by reduction of the endogenous cytokinin content [23-26] or by disruption of cytokinin signalling [6-8,27] show enhanced root growth. In the root apical meristem, cytokinin promotes the transition from cells to differentiation [24,28] acting through the auxin-response factor IAA3/SHY2 [29]. In contrast, cytokinin retards cellular differentiation in the shoot apical meristem by interacting with the WUS/CLV pathway, as well as by a separate pathway [30-33]. Similarly, cytokinin inhibits root branching $[34,35]$, but stimulates the growth of lateral shoots [36]. Moreover, a high cytokinin:auxin ratio favours shoot induction in undifferentiated callus tissue, while a low cytokinin:auxin ratio leads to the formation of roots [37]. In addition to these developmental changes, it has been shown that cytokinin-deficiency has different consequences on the primary metabolism of root and shoot tissue [38].
Different activities of cytokinin in the two organs could be partly realized through a different transcriptional response. Shoots and roots express specific sets of genes [39]. Here we describe the results of a genome-wide expression profiling of roots and shoots of seedlings treated with cytokinin for different periods of time. In addition, we compared the root and shoot transcriptomes of wild-type plants with those of cytokinin-deficient plants overexpressing the cytokinin oxidase/dehydrogenase gene CKX1 under the control of the $35 S$ promoter [24]. We looked for similarities and differences of cytokinin-dependent gene expression in roots and shoots to identify genes with organ-specific regulation, as well as to assign a rootor shoot-specific response to already known cytokininregulated genes. The results of this transcript profiling approach are a starting point for further research into the differential responses of roots and shoots to cytokinin.

\section{Results and discussion}

In order to search for short-term and long-term effects on the transcriptome, we treated 5-d-old wild-type seedlings with cytokinin for 15 min (named BA15), $2 \mathrm{~h}$ (BA120), and $18 \mathrm{~h}$ (BA1080) and harvested roots and shoots separately. To contrast the cytokinin induction, we analyzed root and shoot samples of cytokinindeficient 35S:CKX1 expressing seedlings of the same age (named CKX1). These seedlings contain about 38\% of the cytokinin levels of wild-type seedlings in the roots and about $12 \%$ in the shoots [26]. The reference samples for the whole experiment were roots and shoots of mock-treated wild-type seedlings (BA0). mRNA preparations were obtained from two biological replicates and subjected to microarray analysis as described in Methods. The hybridization strategy used for this study yielded absolute expression values instead of the foldchanges usually obtained from two-colour microarrays. To identify cytokinin-regulated genes, we considered only those transcripts which were detected on at least $25 \%$ of the microarrays (i. e. 8 microarrays for cytokinin induction and 4 microarrays for cytokinin deficiency), because inclusion of weakly expressed genes caused a large number of false positives as determined by reexamination by qRT-PCR (data not shown). In total, 8,549 and 7,557 genes were above the cutoff on the arrays used for the analysis of gene regulation by cytokinin treatment or cytokinin-deficiency, respectively. These genes were then classified as described in Methods and Additional file 1: Figure S1. Genes with more than 2.5-fold change of expression compared to the control samples are listed in Additional file 2: Table S1 (cytokinin induction, 1,450 genes) and Additional file 3: Table S2 (cytokinin deficiency, 1,473 genes), respectively. Selected examples of these genes are listed in Table 1 
Table 1 Organ-specific changes of transcript abundance in response to cytokinin treatment

\begin{tabular}{|c|c|c|c|c|c|c|c|c|c|c|c|}
\hline \multirow[t]{3}{*}{ Category } & \multirow[t]{3}{*}{ CATMA ID } & \multirow[t]{3}{*}{$A b B$} & \multicolumn{6}{|c|}{ Ratio } & \multirow{3}{*}{$\begin{array}{l}\text { FVR p-value } \\
\text { cytokinin effect }\end{array}$} & \multirow[t]{3}{*}{ AGI } & \multirow[t]{3}{*}{ Description } \\
\hline & & & \multicolumn{3}{|c|}{ Root } & \multicolumn{3}{|c|}{ Shoot } & & & \\
\hline & & & $\begin{array}{l}\text { BA15 } \\
\text { vs. } \\
\text { BA0 }\end{array}$ & $\begin{array}{l}\text { BA120 } \\
\text { vs. } \\
\text { BA0 }\end{array}$ & $\begin{array}{l}\text { BA1080 } \\
\text { vs. } \\
\text { BA0 }\end{array}$ & $\begin{array}{l}\text { BA15 } \\
\text { vs. } \\
\text { BA0 }\end{array}$ & $\begin{array}{l}\text { BA120 } \\
\text { vs. } \\
\text { BA0 }\end{array}$ & $\begin{array}{l}\text { BA1080 } \\
\text { vs. } \\
\text { BA0 }\end{array}$ & & & \\
\hline \multirow[t]{15}{*}{ root-specific } & CATMA1a44090 & 9 & 5.71 & 75.18 & 156.88 & 0.74 & 0.47 & 0.52 & $1.81 \mathrm{E}-02$ & AT1G53060 & legume lectin family protein \\
\hline & CATMA1a56420 & 8 & 4.19 & 60.47 & 29.56 & 0.90 & 0.62 & 1.50 & $4.72 \mathrm{E}-03$ & AT1G67110 & cytochrome P450, putative \\
\hline & CATMA2a32630 & 11 & 1.68 & 0.26 & 66.01 & 1.61 & 0.55 & 0.83 & $3.02 \mathrm{E}-07$ & AT2G34490 & cytochrome P450 family protein \\
\hline & CATMA4a38980 & 13 & 6.85 & 21.89 & 16.03 & 1.50 & 1.03 & 0.99 & 4.49E-03 & AT4G37410 & cytochrome P450, putative \\
\hline & CATMA3a15410 & 8 & 0.89 & 19.41 & 3.14 & 1.55 & 1.47 & 0.71 & $2.38 \mathrm{E}-03$ & AT3G15990 & sulfate transporter, putative \\
\hline & CATMA1a29550 & 13 & 0.97 & 6.93 & 9.80 & 0.82 & 0.89 & 1.93 & $1.25 \mathrm{E}-04$ & AT1G31320 & LOB domain protein 4 (LBD4) \\
\hline & CATMA5a61330 & 18 & 2.56 & 8.17 & 5.68 & 1.21 & 0.84 & 1.02 & $5.89 \mathrm{E}-04$ & AT5G65990 & $\begin{array}{l}\text { amino acid transporter family } \\
\text { protein }\end{array}$ \\
\hline & CATMA4a30310 & 28 & 0.99 & 0.86 & 5.08 & 0.65 & 0.54 & 0.81 & $1.31 \mathrm{E}-06$ & AT4G28660 & $\begin{array}{l}\text { photosystem II reaction } \\
\text { centre W (PsbW) family } \\
\text { protein }\end{array}$ \\
\hline & CATMA5a50360 & 21 & 0.49 & 0.64 & 5.65 & 1.00 & 0.56 & 1.16 & $6.90 \mathrm{E}-06$ & AT5G54510 & IAA-amido synthase \\
\hline & CATMA3a26362 & 30 & 0.93 & 0.51 & 4.73 & 0.98 & 0.69 & 1.53 & $1.35 \mathrm{E}-05$ & AT3G26570 & $\begin{array}{l}\text { phosphate transporter } \\
\text { family protein }\end{array}$ \\
\hline & CATMA2a00475 & 24 & 1.15 & 1.12 & 3.41 & 0.62 & 0.61 & 0.55 & 1.67E-02 & AT2G01420 & $\begin{array}{l}\text { auxin transport } \\
\text { protein, putative }\end{array}$ \\
\hline & CATMA4a22880 & 19 & 0.86 & 0.45 & 2.71 & 0.66 & 0.46 & 0.54 & $2.32 \mathrm{E}-04$ & AT4G21280 & $\begin{array}{l}\text { PsbQ subunit of } \\
\text { photosystem II. }\end{array}$ \\
\hline & CATMA4a33000 & 9 & 1.04 & 0.64 & 0.07 & 1.12 & 1.79 & 1.43 & 7.04E-04 & AT4G31320 & $\begin{array}{l}\text { auxin-responsive protein, } \\
\text { putative (SAUR_C) }\end{array}$ \\
\hline & CATMA4a20925 & 12 & 0.95 & 0.35 & 0.04 & 1.39 & 0.74 & 0.71 & 3.39E-04 & AT4G19690 & $\begin{array}{l}\text { iron-responsive } \\
\text { transporter (IRT1) }\end{array}$ \\
\hline & CATMA4a11410 & 6 & 0.82 & 0.24 & 0.08 & 0.93 & 1.14 & 0.97 & $1.09 \mathrm{E}-02$ & AT4G11280 & $\begin{array}{l}\text { 1-aminocyclopropane- } \\
\text { 1-carboxylate (ACC) } \\
\text { synthase }\end{array}$ \\
\hline \multirow[t]{5}{*}{ shoot-specific } & CATMA5a49210 & 6 & 2.28 & 1.71 & 0.79 & 5.42 & 7.91 & 6.22 & $2.53 \mathrm{E}-05$ & AT5G53290 & $\begin{array}{l}\text { ERF subfamily B-5 } \\
\text { of ERF/AP2 transcription } \\
\text { factor }\end{array}$ \\
\hline & CATMA2a30720 & 12 & 0.82 & 2.11 & 0.71 & 5.49 & 6.48 & 7.33 & $7.58 \mathrm{E}-03$ & AT2G32430 & $\begin{array}{l}\text { galactosyltransferase } \\
\text { family protein }\end{array}$ \\
\hline & CATMA5a51700 & 7 & 1.48 & 1.64 & 0.43 & 3.18 & 9.71 & 5.61 & $5.80 \mathrm{E}-03$ & AT5G55920 & $\begin{array}{l}\text { nucleolar protein, } \\
\text { putative }\end{array}$ \\
\hline & CATMAЗа41735 & 22 & 1.00 & 1.37 & 0.64 & 8.68 & 7.88 & 1.83 & $1.21 \mathrm{E}-01$ & AT3G48750 & $\begin{array}{l}\text { A-type cyclin- } \\
\text { dependent kinase }\end{array}$ \\
\hline & CATMA4a19065 & 19 & 2.17 & 1.45 & 0.48 & 3.05 & 6.26 & 4.66 & $1.09 \mathrm{E}-02$ & AT4G18040 & $\begin{array}{l}\text { eukaryotic translation } \\
\text { initiation factor } 4 \mathrm{E} \\
1 \text { (EIF4E1) }\end{array}$ \\
\hline
\end{tabular}


Table 1 Organ-specific changes of transcript abundance in response to cytokinin treatment (Continued)

\begin{tabular}{|c|c|c|c|c|c|c|c|c|c|c|c|}
\hline & CATMA3a10615 & 6 & 0.72 & 1.35 & 0.61 & 2.91 & 5.89 & 3.86 & $2.37 \mathrm{E}-03$ & AT3G11670 & $\begin{array}{l}\text { digalactosyldiacylglycerol } \\
\text { synthase } 1 \text { (DGD1) }\end{array}$ \\
\hline & CATMA1a28980 & 22 & 0.57 & 0.50 & 1.51 & 3.39 & 1.78 & 2.26 & $1.19 \mathrm{E}-02$ & AT1G30840 & purine permease-related \\
\hline & CATMA2а32773 & 9 & 1.19 & 1.14 & 1.69 & 0.83 & 0.34 & 0.34 & $2.80 \mathrm{E}-02$ & AT2G34650 & $\begin{array}{l}\text { protein kinase } \\
\text { PINOID (PID) }\end{array}$ \\
\hline & CATMA5a53690 & 31 & 0.85 & 0.63 & 1.80 & 0.53 & 0.45 & 0.39 & 8.23E-03 & AT5G57930 & $\begin{array}{l}\text { ACCUMULATION OF } \\
\text { PHOTOSYSTEM ONE } \\
2 \text { (APO2) }\end{array}$ \\
\hline & CATMA1a65110 & 29 & 1.04 & 0.79 & 0.54 & 0.34 & 0.32 & 0.09 & $3.96 \mathrm{E}-07$ & AT1G75820 & $\begin{array}{l}\text { CLAVATA1 receptor } \\
\text { kinase (CLV1) }\end{array}$ \\
\hline & CATMA5a43215 & 30 & 0.50 & 0.80 & 0.87 & 0.44 & 0.18 & 0.08 & $3.27 \mathrm{E}-03$ & AT5G47230 & $\begin{array}{l}\text { ERF subfamily B-3 } \\
\text { of ERF/AP2 transcription } \\
\text { factor (ATERF-5) }\end{array}$ \\
\hline & CATMA4a28860 & 31 & 0.53 & 0.50 & 0.85 & 0.26 & 0.17 & 0.07 & $8.86 \mathrm{E}-05$ & AT4G27280 & $\begin{array}{l}\text { calcium-binding EF } \\
\text { hand family protein }\end{array}$ \\
\hline \multirow[t]{2}{*}{ differential } & CATMA4a13955 & 22 & 1.87 & 1.07 & 0.22 & 10.41 & 4.16 & 2.68 & $2.25 \mathrm{E}-04$ & AT4G13770 & $\begin{array}{l}\text { cytochrome P450 } \\
\text { family protein }\end{array}$ \\
\hline & CATMA5a03540 & 10 & 0.71 & 2.78 & 5.07 & 0.44 & 0.18 & 0.50 & $1.01 \mathrm{E}-02$ & AT5G04330 & $\begin{array}{l}\text { cytochrome P450, } \\
\text { putative }\end{array}$ \\
\hline \multirow[t]{12}{*}{ similar } & CATMA5a07985 & 17 & 2.96 & 2.22 & 1.85 & 14.50 & 30.04 & 4.43 & 2.03E-02 & AT5G08640 & $\begin{array}{l}\text { flavonol synthase } 1 \\
\text { (FLS1) }\end{array}$ \\
\hline & CATMA3a18390 & 5 & 2.90 & 12.10 & 4.22 & 9.20 & 4.14 & 2.85 & $1.05 \mathrm{E}-03$ & AT3G18773 & $\begin{array}{l}\text { zinc finger (C3HC4-type } \\
\text { RING finger) family } \\
\text { protein }\end{array}$ \\
\hline & CATMA2b16180 & 13 & 2.72 & 12.21 & 8.03 & 2.92 & 2.72 & 2.64 & $7.70 \mathrm{E}-03$ & AT2G17500 & $\begin{array}{l}\text { auxin efflucarrier } \\
\text { family protein }\end{array}$ \\
\hline & CATMA4a41340 & 17 & 2.58 & 2.26 & 3.97 & 5.32 & 4.92 & 10.72 & $1.08 \mathrm{E}-04$ & AT4G39950 & $\begin{array}{l}\text { cytochrome P450 79B2, } \\
\text { putative (CYP79B2) }\end{array}$ \\
\hline & CATMA1a18090 & 15 & 3.90 & 12.44 & 0.83 & 1.90 & 6.88 & 1.54 & 4.74E-06 & AT1G19050 & response regulator 7 (ARR7) \\
\hline & CATMA2a16180 & 11 & 1.01 & 7.02 & 5.94 & 3.08 & 1.61 & 1.85 & $1.01 \mathrm{E}-02$ & AT2G17500 & $\begin{array}{l}\text { auxin efflucarrier } \\
\text { family protein }\end{array}$ \\
\hline & CATMA4a25920 & 22 & 3.39 & 2.18 & 0.72 & 3.05 & 7.24 & 2.36 & $1.25 \mathrm{E}-04$ & AT4G24190 & shepherd protein (SHD) \\
\hline & CATMA4a20920 & 12 & 1.07 & 1.57 & 3.05 & 1.03 & 4.11 & 7.38 & 1.47E-02 & AT4G19680 & $\begin{array}{l}\text { iron-responsive } \\
\text { transporter (IRT2) }\end{array}$ \\
\hline & CATMA5a46780 & 4 & 0.81 & 4.71 & 2.55 & 2.12 & 2.52 & 4.32 & $1.40 \mathrm{E}-02$ & AT5G50820 & $\begin{array}{l}\text { no apical meristem } \\
\text { (NAM) family protein }\end{array}$ \\
\hline & CATMA5a19900 & 9 & 4.76 & 2.40 & 1.61 & 2.80 & 3.08 & 2.25 & $2.14 \mathrm{E}-02$ & AT5G22440 & $\begin{array}{l}\text { 60S ribosomal } \\
\text { protein L10A (RPL10aC) }\end{array}$ \\
\hline & CATMA2a29850 & 28 & 2.70 & 2.11 & 3.60 & 2.93 & 2.57 & 2.62 & $8.25 \mathrm{E}-03$ & AT2G31610 & $\begin{array}{l}\text { 40S ribosomal } \\
\text { protein S3 (RPS3A) }\end{array}$ \\
\hline & CATMA1a69100 & 20 & 3.03 & 2.52 & 2.38 & 2.11 & 4.75 & 1.72 & 1.99E-02 & AT1G79920 & $\begin{array}{l}\text { heat shock protein 70, } \\
\text { putative (HSP70) }\end{array}$ \\
\hline
\end{tabular}


Table 1 Organ-specific changes of transcript abundance in response to cytokinin treatment (Continued)

\begin{tabular}{|c|c|c|c|c|c|c|c|c|c|c|c|}
\hline & CATMA5a43680 & 27 & 2.66 & 1.68 & 3.14 & 3.01 & 3.43 & 2.48 & $1.43 \mathrm{E}-02$ & AT5G47700 & $\begin{array}{l}605 \text { acidic ribosomal } \\
\text { protein P1 (RPP1C) }\end{array}$ \\
\hline & CATMA4a31370 & 15 & 0.43 & 4.28 & 3.45 & 1.19 & 1.89 & 4.42 & 4.75E-05 & AT4G29740 & $\begin{array}{l}\text { FAD-binding domain- } \\
\text { containing protein }\end{array}$ \\
\hline & CATMA1a48985 & 6 & 0.84 & 3.57 & 4.63 & 2.27 & 1.03 & 3.28 & $2.86 \mathrm{E}-03$ & AT1G59940 & $\begin{array}{l}\text { response regulator } \\
\text { (ARR) }\end{array}$ \\
\hline & CATMA3a45520 & 17 & 2.65 & 1.44 & 2.74 & 1.34 & 2.27 & 2.94 & $1.95 \mathrm{E}-02$ & AT3G52580 & $\begin{array}{l}\text { 40S ribosomal } \\
\text { protein S14 (RPS14C) }\end{array}$ \\
\hline & CATMA1a09860 & 13 & 2.25 & 1.17 & 3.18 & 3.46 & 1.96 & 0.54 & 7.61E-03 & AT1G10970 & $\begin{array}{l}\text { metal transporter, } \\
\text { putative (ZIP4) }\end{array}$ \\
\hline & CATMA3а48290 & 12 & 2.71 & 1.42 & 0.86 & 4.96 & 2.26 & 0.96 & 1.77E-02 & AT3G55280 & $\begin{array}{l}60 S \text { ribosomal } \\
\text { protein L23A (RPL23aB) }\end{array}$ \\
\hline & CATMA2a26520 & 26 & 0.78 & 0.27 & 1.61 & 1.14 & 0.40 & 0.74 & $8.72 \mathrm{E}-05$ & AT2G28120 & nodulin family protein \\
\hline & CATMA4a08040 & 24 & 0.80 & 0.58 & 0.31 & 1.74 & 1.08 & 0.23 & 1.41E-05 & AT4G08290 & $\begin{array}{l}\text { nodulin MtN21 } \\
\text { family protein }\end{array}$ \\
\hline & CATMA4a01650 & 8 & 1.07 & 1.03 & 0.17 & 1.13 & 0.81 & 0.39 & $9.55 \mathrm{E}-03$ & AT4G01450 & $\begin{array}{l}\text { nodulin MtN21 } \\
\text { family protein }\end{array}$ \\
\hline & CATMA2a31475 & 31 & 0.29 & 0.82 & 1.51 & 0.39 & 0.46 & 0.59 & $3.36 \mathrm{E}-03$ & AT2G33310 & $\begin{array}{l}\text { indoleacetic acid- } \\
\text { induced protein } 13 \text { (IAA13) }\end{array}$ \\
\hline & CATMA1a01400 & 10 & 0.62 & 0.84 & 0.26 & 1.12 & 0.36 & 0.27 & $2.11 \mathrm{E}-02$ & AT1G02400 & gibberellin 2-oxidase \\
\hline & CATMA4a08050 & 23 & 0.52 & 0.30 & 0.27 & 1.10 & 0.83 & 0.16 & $9.93 \mathrm{E}-06$ & AT4G08300 & $\begin{array}{l}\text { nodulin MtN21 } \\
\text { family protein }\end{array}$ \\
\hline & CATMA2a25030 & 24 & 0.56 & 0.39 & 0.56 & 0.64 & 0.64 & 0.34 & $4.80 \mathrm{E}-03$ & AT2G26710 & cytochrome p450 family \\
\hline & CATMA1a18780 & 31 & 0.77 & 0.27 & 0.80 & 0.73 & 0.31 & 0.22 & $6.34 \mathrm{E}-05$ & AT1G19770 & purine permease-related \\
\hline & CATMA3а22995 & 31 & 0.63 & 0.37 & 0.57 & 0.35 & 0.48 & 0.69 & $1.67 \mathrm{E}-02$ & AT3G23050 & $\begin{array}{l}\text { indoleacetic acid- } \\
\text { induced protein } \\
7 \text { (IAA7) }\end{array}$ \\
\hline & CATMA5а59720 & 22 & 0.57 & 0.27 & 0.78 & 0.51 & 0.29 & 0.19 & $1.55 \mathrm{E}-04$ & AT5G64260 & $\begin{array}{l}\text { phosphate-responsive } \\
\text { protein, putative }\end{array}$ \\
\hline & CATMA1a66768 & 9 & 1.01 & 0.46 & 0.24 & 0.62 & 0.20 & 0.06 & $8.11 \mathrm{E}-05$ & AT1G77640 & $\begin{array}{l}\text { DREB subfamily A-5 of } \\
\text { ERF/AP2 transcription factor }\end{array}$ \\
\hline & CATMA1a33270 & 21 & 0.78 & 0.11 & 0.16 & 0.55 & 0.27 & 0.60 & $6.69 \mathrm{E}-05$ & AT1G35140 & $\begin{array}{l}\text { phosphate-responsive } \\
\text { protein }\end{array}$ \\
\hline & CATMAЗа25040 & 24 & 0.82 & 0.52 & 0.13 & 0.45 & 0.38 & 0.06 & 7.64E-07 & AT3G25190 & nodulin, putative \\
\hline & CАTMAЗа14910 & 27 & 0.51 & 0.30 & 0.60 & 0.49 & 0.22 & 0.14 & $2.37 \mathrm{E}-04$ & AT3G15500 & $\begin{array}{l}\text { no apical meristem } \\
\text { (NAM) family protein (NAC3) }\end{array}$ \\
\hline \multirow[t]{2}{*}{ similar } & CATMA5a57200 & 28 & 0.65 & 0.33 & 0.60 & 0.32 & 0.12 & 0.09 & $9.30 \mathrm{E}-05$ & AT5G61600 & $\begin{array}{l}\text { ERF subfamily B-3 } \\
\text { of ERF/AP2 transcription } \\
\text { factor }\end{array}$ \\
\hline & CATMA1a26550 & 17 & 0.71 & 0.19 & 0.09 & 0.69 & 0.22 & 0.12 & $1.61 \mathrm{E}-05$ & AT1G28370 & $\begin{array}{l}\text { ERF subfamily B-1 of } \\
\text { ERF/AP2 transcription factor }\end{array}$ \\
\hline
\end{tabular}


Table 1 Organ-specific changes of transcript abundance in response to cytokinin treatment (Continued)

\begin{tabular}{|c|c|c|c|c|c|c|c|c|c|c|c|}
\hline & CATMA3a14565 & 31 & 0.41 & 0.17 & 0.70 & 0.40 & 0.14 & 0.17 & $3.42 \mathrm{E}-04$ & AT3G15210 & $\begin{array}{l}\text { ERF subfamily B-1 } \\
\text { of ERF/AP2 transcription } \\
\text { factor (ATERF-4) }\end{array}$ \\
\hline & CATMA5a47120 & 23 & 0.65 & 0.30 & 0.33 & 0.43 & 0.11 & 0.08 & $2.60 \mathrm{E}-04$ & AT5G51190 & $\begin{array}{l}\text { ERF subfamily B-3 of ERF/ } \\
\text { AP2 transcription factor }\end{array}$ \\
\hline & CATMA5a43205 & 26 & 0.60 & 0.43 & 0.11 & 0.47 & 0.18 & 0.07 & $2.68 \mathrm{E}-06$ & AT5G47220 & $\begin{array}{l}\text { ERF subfamily B-3 } \\
\text { of ERF/AP2 transcription } \\
\text { factor }\end{array}$ \\
\hline & CATMA2a43300 & 20 & 0.42 & 0.64 & 0.21 & 0.36 & 0.15 & 0.05 & $5.73 E-04$ & AT2G44840 & $\begin{array}{l}\text { ERF subfamily B-3 } \\
\text { of ERF/AP2 transcription } \\
\text { factor }\end{array}$ \\
\hline & CATMA3a54340 & 27 & 0.41 & 0.16 & 0.26 & 0.23 & 0.24 & 0.14 & $2.27 \mathrm{E}-03$ & AT3G61190 & $\begin{array}{l}\text { BON1-associated } \\
\text { protein } 1 \text { (BAP1) }\end{array}$ \\
\hline & CATMA5a06800 & 26 & 0.85 & 0.44 & 0.40 & 0.90 & 0.68 & 0.34 & $1.93 \mathrm{E}-06$ & AT5G07580 & $\begin{array}{l}\text { ERF subfamily B-3 } \\
\text { of ERF/AP2 transcription } \\
\text { factor }\end{array}$ \\
\hline \multirow[t]{8}{*}{ uncategorized } & CATMA2a39655 & 8 & 0.93 & 2.15 & 0.27 & 2.78 & 13.61 & 2.65 & $2.87 \mathrm{E}-02$ & AT2G41310 & $\begin{array}{l}\text { response regulator } \\
3 \text { (ARR3) }\end{array}$ \\
\hline & CATMA1a08395 & 15 & 0.58 & 0.52 & 1.31 & 0.32 & 0.37 & 0.39 & $1.12 \mathrm{E}-02$ & AT1G09530 & $\begin{array}{l}\text { phytochrome interacting } \\
\text { factor } 3 \text { (PIF3) }\end{array}$ \\
\hline & CATMA2a37175 & 9 & 2.69 & 4.10 & 0.81 & 2.50 & 1.54 & 0.56 & 1.77E-02 & AT2G38940 & $\begin{array}{l}\text { phosphate transporter } \\
\text { (PT2) }\end{array}$ \\
\hline & CATMA1a68670 & 23 & 1.63 & 1.43 & 1.36 & 2.45 & 3.23 & 3.06 & $2.54 \mathrm{E}-02$ & AT1G79560 & FtsH protease \\
\hline & CATMA5a43410 & 15 & 0.48 & 0.18 & 0.00 & 3.30 & 0.70 & 0.10 & 1.31E-06 & AT5G47450 & $\begin{array}{l}\text { major intrinsic } \\
\text { family protein }\end{array}$ \\
\hline & CATMA2a31585 & 30 & 1.06 & 0.59 & 3.55 & 0.60 & 0.50 & 1.29 & 3.99E-05 & AT2G33430 & $\begin{array}{l}\text { plastid developmental } \\
\text { protein DAG }\end{array}$ \\
\hline & CATMA2a34435 & 28 & 0.96 & 1.00 & 2.51 & 0.86 & 1.27 & 1.22 & 9.89E-05 & AT2G36250 & $\begin{array}{l}\text { chloroplast division } \\
\text { protein FtsZ (FtsZ2-1) }\end{array}$ \\
\hline & CATMA5a43410 & 15 & 0.48 & 0.18 & 0.00 & 3.30 & 0.70 & 0.10 & $1.31 \mathrm{E}-06$ & AT5G47450 & $\begin{array}{l}\text { major intrinsic } \\
\text { family protein }\end{array}$ \\
\hline
\end{tabular}

The table contains an arbitrary selection of genes showing an organ-specific change of transcript abundance in response to cytokinin treatment. A number of these genes are discussed in the text. The categorization of genes was performed as described in Methods and in Additional file 1: Figure S1. Expression ratios in roots and shoots at different time points in relation to the control are given and coded by different font variants: bold, upregulation; italics, downregulation; regular, no regulation. CATMA ID, unique identifier for the gene specific tag (probe) on the microarray (data can be queried under www.catma.org); AbB, number of spots above background (a rough measure for expression strength); AGI, unique gene identifier assigned by TAIR; Description, edited TAIR database annotation. FDR corrected p-values $\leq 0.03$, indicating whether a gene was significantly regulated by cytokinin, are marked with bold numbers. 
Table 2 Organ-specificity of genes differentially expressed in cytokinin-deficient plants

\begin{tabular}{|c|c|c|c|c|c|c|c|}
\hline \multirow[t]{2}{*}{ Category } & \multirow[t]{2}{*}{ CATMA ID } & \multirow[t]{2}{*}{$A b B$} & \multicolumn{2}{|c|}{ Ratio CKX1 vs. Col-0 } & \multirow{2}{*}{$\begin{array}{l}\text { FDR p-value } \\
\text { genotype effect }\end{array}$} & \multirow[t]{2}{*}{ AGI } & \multirow[t]{2}{*}{ Description } \\
\hline & & & Root & Shoot & & & \\
\hline \multirow[t]{8}{*}{ root-specific } & CATMA5a61330 & 11 & 18.32 & 1.26 & $7.99 \mathrm{E}-04$ & AT5G65990 & $\begin{array}{l}\text { amino acid transporter } \\
\text { family protein }\end{array}$ \\
\hline & CATMA3a43475 & 5 & 7.63 & 1.57 & $9.62 \mathrm{E}-06$ & AT3G50410 & $\begin{array}{l}\text { Dof-type zinc finger domain- } \\
\text { containing protein }\end{array}$ \\
\hline & CATMA1a62410 & 4 & 5.66 & 0.63 & 4.99E-02 & AT1G73165 & Clavata3 / ESR-Related-1 (CLE1) \\
\hline & CATMA5a37900 & 7 & 4.72 & 1.07 & 4.77E-03 & AT5G42200 & $\begin{array}{l}\text { zinc finger (C3HC4-type } \\
\text { RING finger) family protein }\end{array}$ \\
\hline & CATMA3a40595 & 4 & 2.86 & 0.97 & $5.65 \mathrm{E}-03$ & AT3G47600 & $\begin{array}{l}\text { myb family transcription } \\
\text { factor (MYB94) }\end{array}$ \\
\hline & CATMA1a66990 & 9 & 2.60 & 0.89 & $5.31 \mathrm{E}-03$ & AT1G77840 & $\begin{array}{l}\text { eukaryotic translation initiation } \\
\text { factor } 5 \text {, putative (elF-5) }\end{array}$ \\
\hline & CATMA4a36496 & 11 & 0.27 & 1.10 & $1.04 \mathrm{E}-02$ & AT4G34680 & $\begin{array}{l}\text { GATA transcription factor } 3 \text {, } \\
\text { putative (GATA-3) }\end{array}$ \\
\hline & CATMA2a45310 & 4 & 0.02 & 1.03 & 1.77E-02 & AT2G46870 & $\begin{array}{l}\text { DNA-binding protein, } \\
\text { putative }\end{array}$ \\
\hline \multirow[t]{19}{*}{ shoot-specific } & CATMA4a00090 & 9 & 1.00 & 76.53 & $1.19 \mathrm{E}-03$ & AT4G00080 & $\begin{array}{l}\text { invertase/pectin methylesterase } \\
\text { inhibitor family protein }\end{array}$ \\
\hline & CATMA5a49170 & 9 & 1.33 & 15.44 & $4.78 \mathrm{E}-03$ & AT5G53250 & $\begin{array}{l}\text { arabinogalactan-protein, } \\
\text { putative (AGP22) }\end{array}$ \\
\hline & CATMA4a26210 & 10 & 1.46 & 12.59 & $1.52 \mathrm{E}-06$ & AT4G24480 & $\begin{array}{l}\text { serine/threonine protein } \\
\text { kinase, putative }\end{array}$ \\
\hline & CATMA4a02865 & 9 & 1.01 & 8.82 & $2.70 \mathrm{E}-03$ & AT4G02560 & $\begin{array}{l}\text { homeobox protein } \\
\text { LUMINIDEPENDENS (LD) }\end{array}$ \\
\hline & CATMA3a15410 & 4 & 0.55 & 8.43 & $1.83 \mathrm{E}-02$ & AT3G15990 & $\begin{array}{l}\text { sulfate transporter, } \\
\text { putative }\end{array}$ \\
\hline & CATMA2a44715 & 11 & 1.63 & 4.29 & $4.50 \mathrm{E}-04$ & AT2G46340 & $\begin{array}{l}\text { phytochrome A supressor } \\
\text { spa1 (SPA1) }\end{array}$ \\
\hline & CATMA2a31150 & 13 & 0.68 & 3.08 & $1.72 \mathrm{E}-02$ & AT2G32950 & COP1 regulatory protein \\
\hline & CATMA2a00475 & 14 & 1.07 & 0.38 & $2.37 \mathrm{E}-02$ & AT2G01420 & $\begin{array}{l}\text { auxin transport protein, } \\
\text { putative }\end{array}$ \\
\hline & CATMA1a08416 & 13 & 0.81 & 0.33 & $2.02 \mathrm{E}-02$ & AT1G09570 & phytochrome A (PHYA) \\
\hline & CATMA3a19415 & 16 & 1.24 & 0.33 & $2.33 \mathrm{E}-02$ & AT3G19820 & $\begin{array}{l}\text { cell elongation protein } \\
\text { DWARF1 / DIMINUTO } \\
\text { (DWF1/DIM) }\end{array}$ \\
\hline & CATMA5a06800 & 13 & 0.59 & 0.20 & $2.63 \mathrm{E}-05$ & AT5G07580 & $\begin{array}{l}\text { ERF subfamily B-3 } \\
\text { of ERF/AP2 transcription } \\
\text { factor }\end{array}$ \\
\hline & CATMA4a18523 & 10 & 0.72 & 0.20 & $2.23 \mathrm{E}-03$ & AT4G17490 & $\begin{array}{l}\text { ERF subfamily B-3 } \\
\text { of ERF/AP2 transcription } \\
\text { factor (ATERF-6) }\end{array}$ \\
\hline & CATMA2a32570 & 16 & 0.69 & 0.18 & $1.82 \mathrm{E}-03$ & AT2G34420 & $\begin{array}{l}\text { chlorophyll A-B } \\
\text { binding protein (LHB1B2) }\end{array}$ \\
\hline & CATMA4a36460 & 15 & 0.99 & 0.17 & $3.19 \mathrm{E}-03$ & AT4G34620 & $\begin{array}{l}\text { ribosomal protein S16 } \\
\text { family protein }\end{array}$ \\
\hline & CATMA2a24825 & 13 & 1.86 & 0.16 & $1.26 \mathrm{E}-02$ & AT2G26500 & $\begin{array}{l}\text { cytochrome b6f complex } \\
\text { subunit (petM), putative }\end{array}$ \\
\hline & CATMA5a60355 & 12 & 0.41 & 0.15 & $2.94 \mathrm{E}-06$ & AT5G64920 & $\begin{array}{l}\text { COP1-interacting } \\
\text { protein (CIP8) }\end{array}$ \\
\hline & CATMA4a22880 & 9 & 1.10 & 0.15 & $4.50 \mathrm{E}-03$ & AT4G21280 & $\begin{array}{l}\text { PsbQ subunit of } \\
\text { photosystem II }\end{array}$ \\
\hline & CATMA5a59535 & 4 & 0.59 & 0.12 & $1.99 \mathrm{E}-04$ & AT5G64040 & $\begin{array}{l}\text { photosystem I reaction } \\
\text { center subunit PSI-N }\end{array}$ \\
\hline & CATMA1a68150 & 7 & 0.70 & 0.11 & $8.69 \mathrm{E}-03$ & AT1G79040 & $\begin{array}{l}10 \mathrm{kDa} \text { PsbR subunit of } \\
\text { photosystem II (PSII) }\end{array}$ \\
\hline
\end{tabular}


Table 2 Organ-specificity of genes differentially expressed in cytokinin-deficient plants (Continued)

\begin{tabular}{|c|c|c|c|c|c|c|c|}
\hline & CATMA5a43205 & 16 & 0.63 & 0.11 & 1.37E-05 & AT5G47220 & $\begin{array}{l}\text { ERF subfamily B-3 } \\
\text { of ERF/AP2 transcription } \\
\text { factor (ATERF-2) }\end{array}$ \\
\hline & CATMA1a68150 & 7 & 0.70 & 0.11 & 8.69E-03 & AT1G79040 & $\begin{array}{l}10 \mathrm{kDa} \text { PsbR subunit } \\
\text { of photosystem II }\end{array}$ \\
\hline & CATMA1a46750 & 13 & 1.38 & 0.06 & $3.91 \mathrm{E}-03$ & AT1G55670 & $\begin{array}{l}\text { photosystem I reaction } \\
\text { center subunit } \mathrm{V}\end{array}$ \\
\hline & CATMA5a43215 & 15 & 0.78 & 0.05 & 7.70E-04 & AT5G47230 & $\begin{array}{l}\text { ERF subfamily B-3 } \\
\text { of ERF/AP2 transcription } \\
\text { factor (ATERF-5) }\end{array}$ \\
\hline & CATMA2a43300 & 11 & 0.52 & 0.04 & $9.62 \mathrm{E}-06$ & AT2G44840 & $\begin{array}{l}\text { ERF subfamily B-3 } \\
\text { of ERF/AP2 transcription } \\
\text { factor }\end{array}$ \\
\hline & CATMA5a57200 & 11 & 0.64 & 0.03 & $3.30 \mathrm{E}-03$ & AT5G61600 & $\begin{array}{l}\text { ERF subfamily B-3 } \\
\text { of ERF/AP2 transcription } \\
\text { factor }\end{array}$ \\
\hline & CATMA5a47120 & 7 & 0.42 & 0.03 & $1.20 \mathrm{E}-03$ & AT5G51190 & $\begin{array}{l}\text { ERF subfamily B-3 } \\
\text { of ERF/AP2 transcription } \\
\text { factor }\end{array}$ \\
\hline similar & CATMA5a07985 & 10 & 16.98 & 57.30 & $3.42 \mathrm{E}-03$ & AT5G08640 & flavonol synthase 1 (FLS1) \\
\hline & CATMA4a10345 & 8 & 24.01 & 16.17 & $1.99 \mathrm{E}-03$ & AT4G10310 & sodium transporter (HKT1) \\
\hline & CATMA5a52815 & 11 & 3.38 & 33.99 & $5.78 \mathrm{E}-05$ & AT5G57090 & $\begin{array}{l}\text { auxin transport protein } \\
\text { (EIR1) (PIN2) }\end{array}$ \\
\hline & CATMA2a45915 & 8 & 4.11 & 26.54 & $5.82 \mathrm{E}-04$ & AT2G47460 & $\begin{array}{l}\text { subgroup } 7 \text { of R2R3-MYB } \\
\text { family (MYB12) }\end{array}$ \\
\hline & CATMA2a32640 & 11 & 3.20 & 25.43 & 2.07E-04 & AT2G34500 & $\begin{array}{l}\text { cytochrome P450 family } \\
\text { protein }\end{array}$ \\
\hline & CATMA1a04035 & 5 & 3.86 & 5.95 & $1.72 \mathrm{E}-02$ & AT1G05180 & $\begin{array}{l}\text { auxin-resistance protein } \\
\text { (AXR1) }\end{array}$ \\
\hline & CATMA5a12150 & 15 & 3.65 & 4.48 & $2.57 \mathrm{E}-04$ & AT5G13930 & chalcone synthase \\
\hline & CATMA3a11725 & 8 & 4.38 & 3.17 & $1.42 \mathrm{E}-02$ & AT3G12750 & zinc transporter (ZIP1) \\
\hline & CATMA3a54340 & 14 & 0.34 & 0.29 & $2.75 \mathrm{E}-02$ & AT3G61190 & $\begin{array}{l}\text { BON1-associated } \\
\text { protein } 1 \text { (BAP1) }\end{array}$ \\
\hline & CATMA1a26550 & 4 & 0.34 & 0.26 & 9.57E-06 & AT1G28370 & $\begin{array}{l}\text { ERF subfamily B-1 } \\
\text { of ERF/AP2 transcription } \\
\text { factor }\end{array}$ \\
\hline & CATMA1a09322 & 10 & 0.30 & 0.29 & $1.19 \mathrm{E}-03$ & AT1G10470 & response regulator 4 (ARR4) \\
\hline & CATMA3a16175 & 16 & 0.17 & 0.38 & $3.92 \mathrm{E}-03$ & AT3G16770 & $\begin{array}{l}\text { ERF subfamily B-2 } \\
\text { of ERF/AP2 transcription } \\
\text { factor (RAP2.3) }\end{array}$ \\
\hline & CATMA5a04585 & 11 & 0.21 & 0.31 & $7.30 \mathrm{E}-03$ & AT5G05410 & $\begin{array}{l}\text { DREB subfamily A-2 } \\
\text { of ERF/AP2 transcription } \\
\text { factor (DREB2A) }\end{array}$ \\
\hline & CATMA3a14565 & 15 & 0.26 & 0.20 & $4.00 \mathrm{E}-03$ & AT3G15210 & $\begin{array}{l}\text { ERF subfamily B-1 } \\
\text { of ERF/AP2 transcription } \\
\text { factor (ATERF-4) }\end{array}$ \\
\hline & CATMA5a58475 & 5 & 0.11 & 0.29 & $6.22 \mathrm{E}-04$ & AT5G62920 & response regulator (ARR6) \\
\hline & CATMA1a66910 & 8 & 0.28 & 0.09 & 7.72E-04 & AT1G77760 & nitrate reductase 1 (NR1) \\
\hline & CATMA1a57435 & 6 & 0.12 & 0.18 & $1.18 \mathrm{E}-03$ & AT1G68050 & $\begin{array}{l}\text { F-box family protein } \\
\text { (FKF1) / adagio } 3 \text { (ADO3) }\end{array}$ \\
\hline & CATMA1b35155 & 7 & 0.19 & 0.05 & $8.13 \mathrm{E}-04$ & AT1G37130 & nitrate reductase 2 (NR2) \\
\hline
\end{tabular}

The table contains an arbitrary selection of genes showing altered transcript abundance under cytokinin deficiency. A number of these genes are discussed in the text. The categorization was performed as described in Methods and in Additional file 1: Figure S1. Expression ratios in roots and shoots of cytokinin-deficient seedlings relative to the wild-type control are given and coded by font variants: bold, upregulation; italics, downregulation; regular, no regulation. CATMA ID, unique identifier for the gene specific tag (probe) on the microarray (data can be queried under www.catma.org); AbB, number of spots above background (a rough measure for expression strength); AGI, unique gene identifier assigned by TAIR; Description, edited TAIR database annotation. FDR corrected $p$-values $\leq 0.03$, indicating whether a gene was significantly regulated by cytokinin, are marked with bold numbers. 
(cytokinin induction) and Table 2 (cytokinin deficiency) and will be commented on further below.

\section{Global expression analysis by principal component analysis}

In order to get an insight into the global structure of the complex dataset of this microarray investigation, we performed a principal component analysis (PCA) on a reduced dataset (see Methods) using the steady-state mRNA levels determined by the application of a common reference hybridization strategy (see Methods). This type of analysis applied to the samples of a microarray experiment typically results in clusters of samples with a similar expression pattern, thereby revealing the main factors that lead to changes in gene expression. Additionally, we performed a support tree (ST) clustering, which served as a confirmation of the PCA.

\section{Cytokinin deficiency has a large and specific influence on the transcriptome}

The results of the PCA show a separation of the dataset into distinct clusters (Figure 1b-e). As expected, the largest distance was found between root and shoot samples confirming the functionality of the PCA (Figure 1b, c, e). The samples of the cytokinin-deficient plants were separated from the wild-type samples on a different axis than the organ effect (Figure $1 \mathrm{~b}-\mathrm{d}$ ). Additionally, they form their own cluster in ST clustering (Figure 1a). The large distance of the cytokinin-deficient samples from the wild-type clusters means that cytokinin deficiency causes a global transcript change to an extent comparable to the difference between roots and shoots.

Taken together, PCA analysis groups the samples into four clusters - wild-type roots, wild-type shoots, cytokinindeficient roots, and cytokinin-deficient shoots - each of which occupies one quadrant of the clustering space (Figure 1b-e).

\section{The cytokinin status influences the organ-specific transcriptome pattern}

Closer examination of the distribution of the samples within the clustering space revealed that a long-term cytokinin treatment of roots and constitutively lowered cytokinin content in shoots causes distinct changes of the gene expression pattern shifting the location of the root and shoot samples in the PCA towards the respective other organ.

Firstly, the long-term cytokinin-treated root sample is located more closely to the shoot coordinates than any other root sample (Figure 1b, c, e). This change indicates that after $18 \mathrm{~h}$ of cytokinin treatment, a shift in gene expression towards a shoot-like pattern has started without gross visible developmental changes having occurred in the tissue. Next, we looked for affected genes and identified these based on their differential expression between untreated roots and shoots ( $\geq 2.5$-fold), their altered expression level after $18 \mathrm{~h}$ of cytokinin treatment ( $\geq 2.5$-fold), and by their p-values of the organ, cytokinin and/or interaction effects $(\leq 0.03)$. The transcripts of 106 genes are regulated in this fashion (Figure 2, Additional file 4: Table S3). Among the 59 genes that are upregulated towards a more shoot-like transcript level in long-term cytokinin-treated roots, we identified genes encoding chloroplast-localized proteins as the major overrepresented gene ontology class (70\% of the regulated genes) (Additional file 5: Figure S2a, Additional file 4: Table S3a). These include genes encoding proteins necessary for plastid proliferation, such as the plastid developmental protein DAG (AT2G33430) and the chloroplast division protein FtsZ (AT2G36250). Conversely, 47 predominantly rootexpressed genes, such as AT5G47450 encoding the tonoplast intrinsic protein TIP2;3 transporting ammonium across the tonoplast (Table 1, Additional file 4: Table S3b, Additional file 6: Figure S3a, b, Additional file 7: Figure S4a, b) [40], are repressed by long-term cytokinin treatment in roots. However, no overrepresented functional GO category could be found among this group of genes. In comparison, only 30 genes acquired a more root-like expression upon cytokinin treatment of shoots (Figure 2) and no shift of the respective sample towards root-like expression was observed in the PCA (Figure 1b-e). No GO category could be found to be overrepresented among these genes.

Secondly, a similar, albeit opposite, developmental shift effect was observed in the shoot sample of cytokinindeficient plants, which is located more closely to the root coordinates than any other shoot sample (Figure 1a - c, e). This global shift of the transcript profile to a more root-like pattern suggests that, beside the visible reduction of shoot growth, a low cytokinin status reduces the "shootyness" of the global transcription pattern. We identified genes displaying a corresponding expression pattern as described above. 246 genes show a more root-like transcript level in shoots of cytokinin-deficient seedlings (Figure 2, Additional file 8: Table S4). Also in this case, the set of 169 genes that was downregulated to a more root-like transcript level contains a high fraction (52\%) of chloroplast-related genes (Additional file 5: Figure S2b, Additional file 8: Table S4b). The gene encoding the PsbR subunit of photosystem II (AT1G79040), for example, is downregulated to about one tenth of its expression level in shoots of cytokinin-deficient plants. Conversely, 77 otherwise predominantly shoot-expressed genes are stronger expressed in cytokinin-deficient roots (Figure 2, Additional file 8: Table S4a), such as PIN2, encoding a root-specific auxin efflux carrier discussed further below, but no functional GO category was found to be overrepresented among them. 


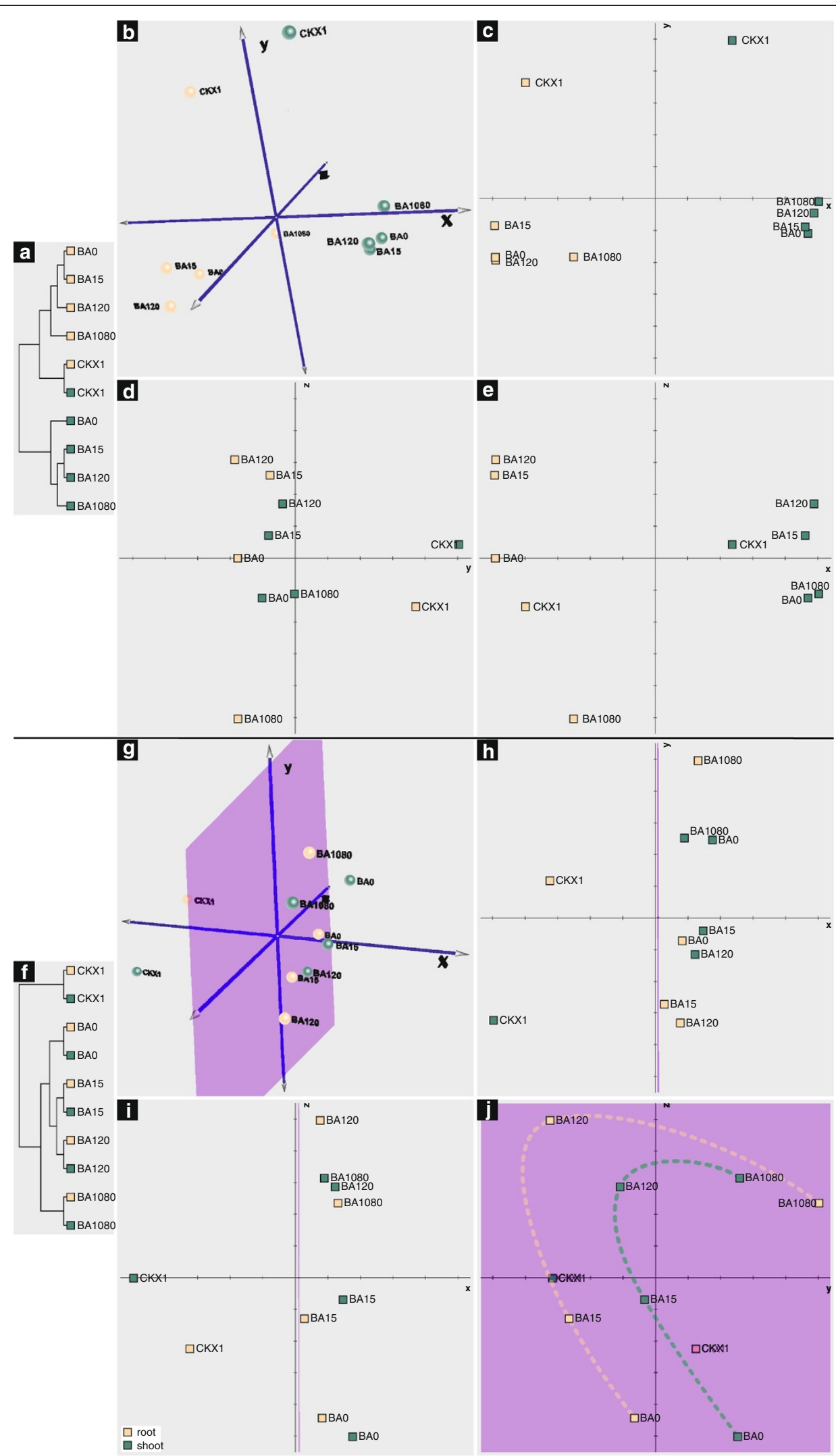

Figure 1 (See legend on next page.) 
(See figure on previous page.)

Figure 1 Clustering and principal component analysis of the samples used for transcript profiling. The analysis was carried out with 911 cytokinin-regulated genes that were selected as described in Methods. (a-e) Analysis using the native dataset. (f-j) Analysis using the dataset after normalization for the organ effect. (a, $\mathbf{f})$ Support tree clustering for the samples. (b-e, $\mathbf{g}$-h) Results of the principal component analyses. (b, $\mathbf{g}$ ) Three-dimensional representation of the results of the principal component analyses. (c-e, $\mathbf{h}-\mathbf{j})$ Two-dimensional plots showing each possible combination of the three dimensions. (c, h) Plots centred on the $x$-axis; $(\mathbf{d}, \mathbf{i})$ plots centred on the $y$-axis; $(\mathbf{e}, \mathbf{j})$ plots centred on the $z$-axis of $(\mathbf{b})$ and (g), respectively. Each point represents an experimental condition, averaging two microarray replicates of two biological replicates. BAO, control; BA15, 15 min of cytokinin treatment; BA120, 2 h of cytokinin treatment; BA1080, 18 h of cytokinin treatment; CKX1, cytokinin oxidase/ dehydrogenase overexpressors. Green, shoot samples; ochre, root samples. The purple markings represent the plane on which the wild-type samples are arranged. The dashed lines in (j) show the factors of global gene expression changes in roots and shoots, respectively. The eigenvalues, which indicate how much of the total variation of the dataset is covered by the respective axis are for $b-e: x, 0.490 ; y, 0.184 ; z, 0.112$; and for $\mathrm{g}$-h: $\mathrm{x}, 0.269 ; \mathrm{y}, 0.239 ; z, 0.179$. A PCA with a more restricted dataset containing 637 genes (i.e. all genes detected on at least $50 \%$ of the arrays) yielded a similar result (data not shown).

Interestingly, 63 of all regulated genes showing an enhanced transcript level in cytokinin-treated roots were also repressed in cytokinin-deficient shoots and vice versa indicating that these are particularly cytokinin-sensitive genes (Table 3). 34 of the 44 genes enhanced by cytokinin in roots and repressed in cytokinin-deficient shoots encode plastid proteins with functions e.g. in the light reaction or the calvin cycle as well as several plastidal ribosomal proteins (Table 3). Examples of the 19 genes repressed by cytokinin in roots and enhanced in cytokinin-deficient shoots encode the predominantly root-expressed sodium transporter HKT1 discussed further below, and the signalling protein CBL-interacting protein kinase 23 (CIPK23, AT1G30270).

The fact that cytokinin deficiency results in downregulation of chloroplast genes in green tissue, whereas excess cytokinin causes chloroplast genes expressed in the root is consistent with a primary role of cytokinin in regulating plastid development [41]. It is noteworthy that only a fraction (3.5\%) of the ca. 3,000 nuclear genes encoding plastidic proteins [42] were affected by an altered cytokinin status, suggesting that cytokinin acts only on part of the genes and/or that there is a sequential order of cytokinin- regulated gene expression of which we detected only a part at the analyzed time point. Consistent with our data others found also a strong increase of genes encoding plastid proteins in cytokinin-treated root callus tissue, albeit at much later time points $[10,43]$. The expression of a comparatively small number of genes was shifted towards a more shootlike profile in cytokinin-deficient roots (Figure 2), and correspondingly no shift of the cytokinin-deficient root sample towards the shoot coordinates was observed in the PCA (Figure 1b-e).

Taken together, these findings indicate that the cytokinin status apparently determines a more root- or shootlike transcriptomic pattern that is at least partially independent of morphologically discernable altered organ identity. We used the category of nuclear genes encoding plastid proteins as a diagnostic tool to assess the "shootyness" of the transcriptome but it is impossible to determine whether the transcriptomic shift in "shootyness" is cause or consequence of a shift in organ identity. However, several studies dissecting the temporal pattern of gene expression during cytokinin-induced shoot development from root calli found that shoot marker genes start to be upregulated only several days

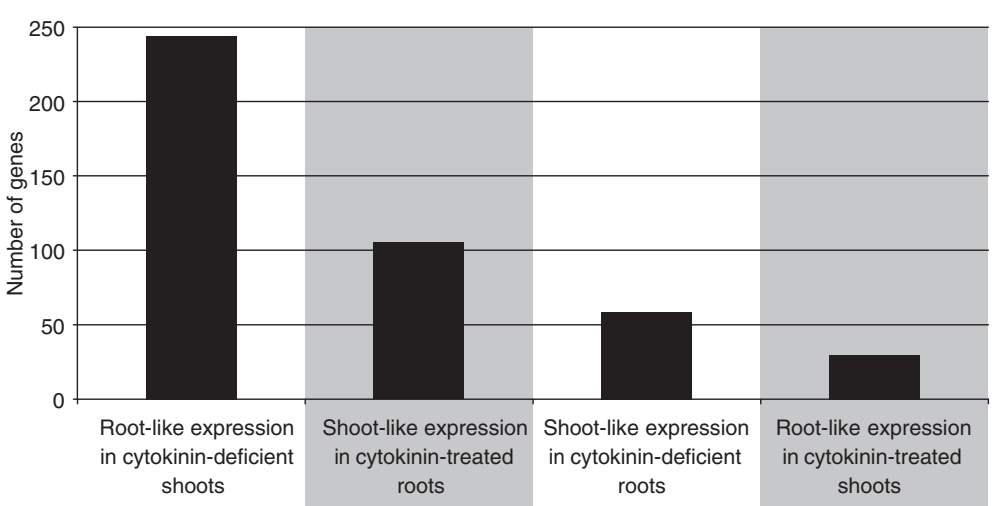

Figure 2 Numbers of genes indicative of a developmental shift. The diagram shows the numbers of genes regulated in fashion of the respective other organ in response to long-term cytokinin treatment or chronic cytokinin deficiency. Genes were selected according to the following criteria: They were differentially expressed in untreated roots and shoots, their expression level was altered $\geq 2.5$-fold after $18 \mathrm{~h}$ of cytokinin treatment, and their p-values of the organ, cytokinin and/or interaction effects were $\leq 0.03$. 
Table 3 Genes indicative of a developmental shift due to an altered cytokinin status

\begin{tabular}{|c|c|c|c|c|c|c|c|c|c|c|}
\hline \multirow[t]{2}{*}{ CATMA ID } & \multirow[t]{2}{*}{ AbB } & \multicolumn{3}{|c|}{ Ratio } & \multicolumn{3}{|c|}{ FDR p-value } & \multirow[t]{2}{*}{ AGI } & \multirow{2}{*}{$\begin{array}{l}\text { Subcellular } \\
\text { localization }\end{array}$} & \multirow[t]{2}{*}{ Description } \\
\hline & & $\begin{array}{c}\text { BA1080 } \\
\text { vs. } \\
\text { BA0 Root }\end{array}$ & $\begin{array}{c}\text { CKX1 } \\
\text { vs. } \\
\text { BA0 Shoot }\end{array}$ & $\begin{array}{c}\text { Root } \\
\text { vs. } \\
\text { Shoot @ BA0 }\end{array}$ & $\begin{array}{l}\text { Cytokinin } \\
\text { effect }\end{array}$ & $\begin{array}{l}\text { Organ } \\
\text { effect }\end{array}$ & $\begin{array}{l}\text { Interaction } \\
\text { effect }\end{array}$ & & & \\
\hline CATMA2a26583 & 40 & 2.71 & 0.09 & 0.04 & $5.78 \mathrm{E}-07$ & $3.27 \mathrm{E}-11$ & $1.12 \mathrm{E}-06$ & AT2G28190 & $a, P$ & $\begin{array}{l}\text { superoxide dismutase (Cu-Zn) } \\
\text { (SODCP) }\end{array}$ \\
\hline CATMA5a16150 & 35 & 2.80 & 0.09 & 0.03 & $1.83 \mathrm{E}-06$ & $5.98 \mathrm{E}-18$ & 2.95E-05 & AT5G17870 & $P$ & $\begin{array}{l}\text { plastid-specific ribosomal } \\
\text { protein-related }\end{array}$ \\
\hline CATMA3a44603 & 29 & 2.71 & 0.12 & 0.00 & $4.68 \mathrm{E}-03$ & $2.58 \mathrm{E}-21$ & 5.67E-05 & AT3G51600 & w & $\begin{array}{l}\text { nonspecific lipid transfer } \\
\text { protein } 5 \text { (LTP5) }\end{array}$ \\
\hline CATMA1a65310 & 37 & 4.44 & 0.14 & 0.01 & $3.01 \mathrm{E}-11$ & $1.64 \mathrm{E}-29$ & $2.54 \mathrm{E}-10$ & AT1G76080 & $P$ & thioredoxin family protein \\
\hline CATMA2a35500 & 34 & 3.08 & 0.13 & 0.07 & $2.34 \mathrm{E}-06$ & $5.32 \mathrm{E}-13$ & $2.70 \mathrm{E}-04$ & AT2G37220 & P & $29 \mathrm{kDa}$ ribonucleoprotein \\
\hline CATMA1a13920 & 37 & 2.76 & 0.13 & 0.20 & $8.52 \mathrm{E}-05$ & 7.32E-05 & 4.18E-04 & AT1G14890 & - & $\begin{array}{l}\text { invertase/pectin methylesterase } \\
\text { inhibitor family protein }\end{array}$ \\
\hline CATMA1a19333 & 37 & 3.21 & 0.14 & 0.01 & $3.04 \mathrm{E}-06$ & $6.27 \mathrm{E}-22$ & $9.90 \mathrm{E}-06$ & AT1G20340 & P & plastocyanin \\
\hline CATMA4a22880 & 23 & 2.73 & 0.14 & 0.01 & $3.41 \mathrm{E}-06$ & $5.25 \mathrm{E}-25$ & 7.49E-06 & AT4G21280 & P & PsbQ subunit of photosystem II \\
\hline CATMA2a04295 & 38 & 2.74 & 0.15 & 0.03 & $8.82 \mathrm{E}-04$ & $3.72 \mathrm{E}-19$ & $6.27 \mathrm{E}-06$ & AT2G05520 & e & glycine-rich protein (GRP) \\
\hline CATMA5a07300 & 33 & 6.42 & 0.35 & 0.01 & $5.78 \mathrm{E}-05$ & $2.59 \mathrm{E}-21$ & $1.92 \mathrm{E}-06$ & AT5G08050 & $P$ & expressed protein \\
\hline CATMA5a12555 & 27 & 3.74 & 0.18 & 0.02 & 8.15E-06 & $1.76 \mathrm{E}-21$ & $2.42 \mathrm{E}-06$ & AT5G14320 & $P$ & $\begin{array}{l}30 \text { ribosomal protein S13, } \\
\text { chloroplast (CS13) }\end{array}$ \\
\hline CATMA4a30310 & 36 & 5.11 & 0.25 & 0.01 & $3.41 \mathrm{E}-06$ & $6.23 \mathrm{E}-24$ & $4.24 \mathrm{E}-06$ & AT4G28660 & $P$ & $\begin{array}{l}\text { photosystem II reaction centre } \\
\text { W (PsbW) family protein }\end{array}$ \\
\hline CATMA3b54606 & 36 & 2.96 & 0.17 & 0.01 & $2.16 \mathrm{E}-02$ & 1.77E-21 & 5.67E-05 & AT3G61470 & $P$ & $\begin{array}{l}\text { chlorophyll A-B binding protein } \\
\text { (LHCA2) }\end{array}$ \\
\hline CATMA3a14550 & 40 & 3.01 & 0.19 & 0.04 & $7.16 \mathrm{E}-06$ & $4.96 \mathrm{E}-20$ & 3.23E-04 & AT3G15190 & P & chloroplast 30 S ribosomal protein $\$ 20$ \\
\hline CATMA2a41430 & 36 & 3.74 & 0.22 & 0.04 & $3.50 \mathrm{E}-05$ & 4.69E-18 & $2.18 \mathrm{E}-04$ & AT2G43030 & $P$ & ribosomal protein L3 family protein \\
\hline CATMA4a26750 & 18 & 2.92 & 0.19 & 0.03 & $1.59 \mathrm{E}-05$ & $2.30 \mathrm{E}-20$ & 8.52E-05 & AT4G25050 & $P$ & $\begin{array}{l}\text { acyl carrier protein predominantly } \\
\text { expressed in leaves }\end{array}$ \\
\hline CATMA2a35140 & 30 & 3.69 & 0.23 & 0.03 & $2.86 \mathrm{E}-05$ & 4.06E-18 & $9.10 \mathrm{E}-04$ & AT2G36870 & $a, e, w$ & xyloglucan:xyloglucosyl transferase \\
\hline CATMA1a63880 & 31 & 3.32 & 0.22 & 0.04 & 7.39E-04 & 2.67E-18 & $9.61 \mathrm{E}-05$ & AT1G74470 & $P$ & geranylgeranyl reductase \\
\hline CATMA4a18000 & 32 & 4.95 & 0.35 & 0.01 & $2.52 \mathrm{E}-06$ & $1.37 \mathrm{E}-22$ & 8.09E-06 & AT4G16980 & e & arabinogalactan-protein family \\
\hline CATMA5a51450 & 30 & 2.74 & 0.20 & 0.05 & $1.20 \mathrm{E}-03$ & 8.97E-17 & $7.88 \mathrm{E}-05$ & AT5G55700 & P & similar to beta-amylase (CT-BMY) \\
\hline CATMA4a40410 & 32 & 2.58 & 0.19 & 0.01 & $1.30 \mathrm{E}-05$ & $8.94 \mathrm{E}-23$ & $1.90 \mathrm{E}-04$ & AT4G38970 & $\mathrm{a}, \mathrm{P}$ & fructose-bisphosphate aldolase \\
\hline CATMA2a37967 & 40 & 2.68 & 0.20 & 0.02 & $1.15 \mathrm{E}-05$ & $2.09 \mathrm{E}-22$ & 3.60E-05 & AT2G39730 & $a, n, P, w$ & RuBisCO activase \\
\hline CATMA1a36300 & 39 & 3.16 & 0.23 & 0.01 & $2.11 \mathrm{E}-04$ & $1.04 \mathrm{E}-22$ & 8.53E-05 & AT1G42970 & $\mathrm{a}, \mathrm{P}$ & $\begin{array}{l}\text { glyceraldehyde-3-phosphate } \\
\text { dehydrogenase B (GAPB) }\end{array}$ \\
\hline CATMA1a27050 & 40 & 4.20 & 0.29 & 0.03 & $6.60 \mathrm{E}-07$ & 4.24E-22 & $7.68 \mathrm{E}-06$ & AT1G29070 & $P$ & ribosomal protein L34 family protein \\
\hline CATMA1a64335 & 34 & 4.00 & 0.29 & 0.03 & 8.82E-06 & 1.17E-20 & $1.03 \mathrm{E}-05$ & AT1G74970 & $P$ & ribosomal protein S9 (RPS9) \\
\hline
\end{tabular}


Table 3 Genes indicative of a developmental shift due to an altered cytokinin status (Continued)

\begin{tabular}{|c|c|c|c|c|c|c|c|c|c|c|}
\hline CATMA5а36620 & 34 & 4.23 & 0.32 & 0.03 & $3.06 \mathrm{E}-05$ & $3.96 \mathrm{E}-21$ & 7.34E-06 & AT5G40950 & $P$ & $\begin{array}{l}50 S \text { ribosomal protein L27, chloroplast } \\
\text { (RPL27) }\end{array}$ \\
\hline CATMA5a39880 & 34 & 3.01 & 0.23 & 0.07 & 8.93E-05 & 1.17E-15 & $1.19 \mathrm{E}-07$ & AT5G44130 & $w, p$ & fasciclin-like arabinogalactan-protein \\
\hline CATMA1a13350 & 28 & 3.28 & 0.26 & 0.01 & $1.31 \mathrm{E}-05$ & $3.61 E-19$ & $6.76 \mathrm{E}-05$ & AT1G14345 & P & $\begin{array}{l}\text { expressed protein, one transmembrane } \\
\text { domain }\end{array}$ \\
\hline CATMA3a11290 & 38 & 2.98 & 0.25 & 0.02 & $2.46 \mathrm{E}-05$ & $5.34 \mathrm{E}-22$ & $6.59 \mathrm{E}-05$ & AT3G12340 & P & immunophilin-related \\
\hline CATMA4a01510 & 23 & 2.96 & 0.25 & 0.06 & 2.93E-05 & $1.70 \mathrm{E}-18$ & $1.06 \mathrm{E}-03$ & AT4G01310 & $c, P$ & ribosomal protein L5 family protein \\
\hline CATMA4a23520 & 29 & 3.77 & 0.32 & 0.05 & 5.33E-02 & $1.68 \mathrm{E}-12$ & $8.70 \mathrm{E}-05$ & AT4G21860 & $P$ & $\begin{array}{l}\text { methionine sulfoxide reductase } \\
\text { domain protein }\end{array}$ \\
\hline CATMA4a26465 & 34 & 4.05 & 0.35 & 0.05 & $2.79 \mathrm{E}-05$ & $7.36 \mathrm{E}-18$ & 4.05E-04 & AT4G24770 & $P$ & $31 \mathrm{kDa}$ ribonucleoprotein \\
\hline CATMA1a60820 & 32 & 3.12 & 0.27 & 0.03 & $2.10 \mathrm{E}-02$ & $3.18 \mathrm{E}-19$ & 8.43E-05 & AT1G71500 & $P$ & $\begin{array}{l}\text { Rieske (2Fe-2S) domain-containing } \\
\text { protein }\end{array}$ \\
\hline CATMA4a17230 & 37 & 3.28 & 0.30 & 0.03 & $5.81 \mathrm{E}-05$ & $1.22 \mathrm{E}-19$ & $6.59 \mathrm{E}-05$ & AT4G16410 & - & expressed protein \\
\hline CATMA2a00475 & 32 & 3.43 & 0.35 & 0.20 & $1.16 \mathrm{E}-04$ & $1.64 \mathrm{E}-10$ & $3.85 \mathrm{E}-05$ & AT2G01420 & - & auxin transport protein \\
\hline CATMA4a21620 & 29 & 2.96 & 0.30 & 0.06 & $3.23 \mathrm{E}-04$ & $2.54 \mathrm{E}-19$ & 8.87E-05 & AT4G20360 & $a, n, P$ & elongation factor Tu (TUFA) \\
\hline CATMA1a00590 & 36 & 2.96 & 0.32 & 0.11 & $5.48 \mathrm{E}-05$ & $1.14 \mathrm{E}-15$ & $1.85 \mathrm{E}-07$ & AT1G01610 & - & glycerol-3-phosphate acyltransferase \\
\hline CATMA1a67690 & 35 & 2.73 & 0.29 & 0.04 & $2.94 \mathrm{E}-03$ & $1.49 \mathrm{E}-20$ & 8.53E-05 & AT1G78630 & $P$ & ribosomal protein L13 family protein \\
\hline CATMA1a67475 & 33 & 3.48 & 0.39 & 0.23 & $1.49 \mathrm{E}-05$ & $5.10 \mathrm{E}-08$ & $3.19 \mathrm{E}-04$ & AT1G78380 & $c, P, p, V$ & glutathione S-transferase, putative \\
\hline CATMA2a30900 & 35 & 2.63 & 0.31 & 0.08 & $1.43 \mathrm{E}-05$ & $2.00 \mathrm{E}-17$ & $1.10 \mathrm{E}-02$ & AT2G32180 & P & expressed protein \\
\hline CATMAЗа20410 & 34 & 2.69 & 0.32 & 0.10 & 8.23E-06 & 8.91E-16 & 8.79E-05 & AT3G20680 & P & expressed protein \\
\hline CATMA5a19250 & 39 & 2.55 & 0.32 & 0.17 & $3.50 \mathrm{E}-04$ & 4.39E-14 & 8.94E-05 & AT5G20720 & $\mathrm{a}, \mathrm{M}, \mathrm{P}$ & 20 kDa chaperonin (CPN21) \\
\hline CATMA3а52950 & 31 & 2.72 & 0.36 & 0.21 & 4.03E-05 & $7.38 \mathrm{E}-12$ & $6.45 \mathrm{E}-05$ & AT3G59940 & - & $\begin{array}{l}\text { kelch repeat-containing F-box } \\
\text { family protein }\end{array}$ \\
\hline CATMA1a30400 & 31 & 2.66 & 0.36 & 0.01 & $5.00 \mathrm{E}-05$ & $1.33 \mathrm{E}-23$ & $5.57 \mathrm{E}-03$ & AT1G32060 & $\mathrm{a}, \mathrm{P}$ & phosphoribulokinase (PRK) \\
\hline CATMA5a43410 & 23 & 0.00 & 17.15 & 278.19 & 4.95E-09 & $2.53 \mathrm{E}-13$ & 0.046445 & AT5G47450 & $v$ & major intrinsic family protein \\
\hline CATMA3а46940 & 19 & 0.02 & 10.04 & 116.88 & $7.21 \mathrm{E}-06$ & $6.92 \mathrm{E}-12$ & 0.024062 & AT3G53980 & e & $\begin{array}{l}\text { lipid transfer protein (LTP) } \\
\text { family protein }\end{array}$ \\
\hline CATMA3а00185 & 23 & 0.08 & 12.14 & 141.58 & $1.49 \mathrm{E}-08$ & $8.53 E-21$ & $6.09 \mathrm{E}-06$ & AT3G01190 & e & peroxidase 27 (PER27) \\
\hline CATMA3a23750 & 16 & 0.11 & 25.69 & 233.14 & $1.38 \mathrm{E}-05$ & $4.82 \mathrm{E}-16$ & 0.00675 & AT3G23800 & - & selenium-binding family protein \\
\hline CATMA1a40940 & 11 & 0.14 & 17.74 & 11.32 & $2.3 \mathrm{E}-05$ & $1.52 \mathrm{E}-05$ & 0.011573 & AT1G49860 & c & glutathione S-transferase \\
\hline CATMA1a28300 & 19 & 0.24 & 4.60 & 11.59 & $5.14 \mathrm{E}-05$ & $2.23 \mathrm{E}-08$ & 0.021175 & AT1G30270 & $c, n, p$ & $\begin{array}{l}\text { CBL-interacting protein } \\
\text { kinase } 23 \text { (CIPK23) }\end{array}$ \\
\hline CATMA5а08890 & 20 & 0.24 & 32.72 & 56.89 & $2.23 \mathrm{E}-10$ & $6.53 \mathrm{E}-18$ & 2.93E-05 & AT5G10130 & $e, x$ & $\begin{array}{l}\text { pollen Ole e } 1 \text { allergen and } \\
\text { extensin family protein }\end{array}$ \\
\hline CATMA2a25985 & 17 & 0.26 & 11.72 & 28.97 & $5.25 \mathrm{E}-06$ & $7.78 \mathrm{E}-13$ & 0.473892 & AT2G27550 & - & centroradialis protein (CEN) \\
\hline CATMA1a22610 & 22 & 0.28 & 36.53 & 105.82 & 7.83E-06 & 4.44E-15 & 0.000233 & AT1G23720 & w & $\begin{array}{l}\text { proline-rich extensin-like } \\
\text { family protein }\end{array}$ \\
\hline
\end{tabular}


Table 3 Genes indicative of a developmental shift due to an altered cytokinin status (Continued)

\begin{tabular}{|c|c|c|c|c|c|c|c|c|c|c|}
\hline CATMA3a23170 & 25 & 0.29 & 13.03 & 75.65 & 7.07E-07 & $3.96 \mathrm{E}-21$ & $1.58 \mathrm{E}-06$ & AT3G23175 & $E$ & lesion inducing protein-related \\
\hline CATMA1a61170 & 22 & 0.30 & 2.78 & 3.42 & 8.77E-07 & $1.88 \mathrm{E}-07$ & 0.468587 & AT1G71960 & $\mathrm{p}$ & $\mathrm{ABC}$ transporter family protein \\
\hline CATMA2a37070 & 24 & 0.31 & 11.75 & 27.66 & $7.75 \mathrm{E}-05$ & $3.99 \mathrm{E}-13$ & 0.000278 & AT2G38800 & - & calmodulin-binding protein-related \\
\hline CATMA1a44600 & 16 & 0.31 & 4.16 & 4.65 & $4.64 \mathrm{E}-05$ & $1.63 \mathrm{E}-05$ & 0.014032 & AT1G53590 & $v$ & C2 domain-containing protein \\
\hline CATMA4a10345 & 14 & 0.34 & 17.87 & 38.52 & $3.41 \mathrm{E}-06$ & $2.36 \mathrm{E}-10$ & 0.071489 & AT4G10310 & $p$ & sodium transporter (HKT1) \\
\hline CATMA5a06070 & 27 & 0.34 & 2.56 & 3.11 & $3.47 E-08$ & $1.77 \mathrm{E}-11$ & 0.307964 & AT5G06850 & - & C2 domain-containing protein \\
\hline CATMA1a04113 & 20 & 0.35 & 2.71 & 21.16 & $2.8 \mathrm{E}-05$ & $8.54 \mathrm{E}-17$ & 0.079992 & AT1G05260 & E & peroxidase 3 (PER3) \\
\hline CATMA1a28520 & 23 & 0.36 & 5.05 & 5.28 & $3.41 \mathrm{E}-06$ & $4 \mathrm{E}-11$ & $2.69 \mathrm{E}-05$ & AT1G30510 & $P$ & ferredoxin-NADP(+) reductase \\
\hline CАTMA3a48230 & 23 & 0.37 & 7.91 & 20.28 & 2.97E-06 & $5.49 \mathrm{E}-15$ & 0.027924 & AT3G55230 & e & $\begin{array}{l}\text { disease resistance-responsive } \\
\text { family protein }\end{array}$ \\
\hline CATMA5а09320 & 11 & 0.37 & 5.73 & 13.92 & $4.28 \mathrm{E}-08$ & $1.53 \mathrm{E}-17$ & $2.74 \mathrm{E}-05$ & AT5G10580 & e & expressed protein \\
\hline
\end{tabular}

The table shows a list of genes, which have both a more shoot-like transcript level in long-term cytokinin-treated roots (Additional file 4: Table S3) and a more root-like transcript level in cytokinin-deficient shoots (Additional file 8: Table S4). Expression ratios are given for long-term cytokinin-treated roots and for cytokinin-deficient shoots in comparison to the mock-treated wild-type samples, as well as for the difference between roots and shoots. The expression ratios are coded: by different font variants: bold, up-regulation; italic, downregulation, regular, no regulation. The FDR-corrected p-values for the cytokinin effect indicate whether a gene was significantly regulated by cytokinin. The FDR-corrected p-values for the organ effect indicate whether the expression level of a gene was significantly different in roots and shoots. The

FDR-corrected $p$-value for the interaction effect indicates whether cytokinin-dependent gene regulation was dependent on the organ. FDR-corrected $p$-values $\leq 0.03$ were regarded as significant and marked with bold numbers.. CATMA ID, unique identifier for the gene specific tag (probe) on the microarray (data can be queried under www.catma.org); AbB, number of spots above background (a rough measure for expression

strength); AGI, unique gene identifier assigned by TAIR; Description, edited TAIR database annotation. Abbreviations for the subcellular localization are: a, apoplast; c, cytosol; E, endoplasmatic reticulum; $\mathrm{e}_{\text {, }}$

endomembrane system; $M$, mitochondrium; $n$, nucleus; $P$, plastid; $p$, plasma membrane; $v$, vacuole; $w$, cell wall; $x$, extracellular space; - , not available or unknown. 
after the onset of the hormonal treatment [10,44-46] supporting the notion that during the time period analyzed here no shoot identity was obtained by the cytokinin-treated root tissue.

\section{Similarity of the overall transcriptional response of roots and shoots to cytokinin}

The effect of cytokinin treatment at different time points was not resolved in the PCA analysis, because the large organ and genotype effects prevailed. Therefore, we removed the largest effect - the organ effect - by normalizing the root and shoot samples for each experimental condition as described in Methods. As a result, support tree clustering showed distinct root-shoot-pairs at each experimental condition indicating that the overall transcriptional response to cytokinin is similar in roots and shoots (Figure 1f). The two early time points of cytokinin induction showed the closest relation, while the long-term treated samples separated from the other wild-type samples.

PCA analysis using this dataset normalized for the organ effect resolved two temporal phases of the transcriptomic response to cytokinin. For the early time points of cytokinin induction, the separation is approximately parallel to the $\mathrm{z}$-axis and for the later time points parallel to the $y$-axis, suggesting that the late response affects a different set of genes than the early response (Figure 1j). Both root and shoot samples follow a similar pattern (shown as dashed lines in Figure 1j), indicating that the transcriptomic response to cytokinin treatment is similar in both organs. This conclusion was confirmed by an additional PCA without the cytokinin-deficient samples, where the arrangement of the wild-type samples in one plane remained stable (data not shown).

Given the fundamental differences of the growth response of roots and shoots to cytokinin, we initially hypothesized that this could be reflected by large differences at the transcriptome level. In fact, cytokinin response genes are regulated by the hormone in a context-dependent manner [47], which is likely due to the presence of multiple cis-regulatory elements in their promoters. Indeed, the only known cytokinin response element is not present in the promoters of all cytokinin responsive genes [19], suggesting that a variety of possibilities exist to regulate a gene by cytokinin. It might well have been possible that large specific subsets of genes are regulated by cytokinin in an organ-specific manner. However, that appears not to be the case. Therefore it is remarkable and to some extent unexpected that the global transcriptional responses in both organs appear to be rather similar. This indicates that it is not the differential bulk expression determining the rather different cytokinin-dependent growth responses in both organs. This would also imply that cytokinin signaling to the nucleus is to a large extent similar and that organ-specific features are limited to few changes, which regulate the growth response. It would be very interesting to find out how these comparably small differences can drive completely different growth responses in roots and shoots. Furthermore, because of these relatively small differences one can expect a relatively low number of genes that are regulated by cytokinin in an organ-specific manner.

It should be noted that the absolute expression level of the genes, although showing qualitatively similar cytokinin responses, can be quite different in roots and shoots (Additional file 2: Table S1 and Additional file 3: Table S2). For instance, the transcripts encoding the auxin transporter PIN2 or the tonoplast intrinsic protein TIP2;3 are more than hundred-fold more abundant in the root than in the shoot, while the phosphate transporter gene PHT2; 1 shows a much higher expression level in the shoot (Additional file 6: Figure S3, Additional file 7: Figure S4). Thus the differential response of the tissues to cytokinin may be affected by additional factors that regulate the absolute abundances of the different messages.

\section{Chronic cytokinin deficiency and cytokinin induction affect different sets of genes}

The PCA of the normalized dataset (Figure 1g-j) shows that the CKX samples separate from the wild-type samples along the $\mathrm{X}$-axis while the effects of cytokinin treatment on the transcriptome are distributed over the $y$ - and z-axes and remain within the same plane (Figure 1g-j, purple markings). This means that the transcriptomic changes resulting from chronic cytokinin deficiency are not simply the opposite of those resulting from early or late cytokinin treatment, but that another (third) set of genes is affected. Consequently, we analyzed cytokinin-deficiency separately from the dataset derived from the cytokinin-induced plants.

\section{Regulation of cytokinin metabolism and signalling genes}

To search for potential homeostatic mechanisms within the cytokinin system, we studied the influence of cytokinin treatment and cytokinin deficiency on the transcript level of cytokinin metabolism and signalling genes (Figure 3). Unfortunately, the CATMA microarray lacks a part of these cytokinin-related genes and expression of another part was below the detection limit. Therefore, only a limited number of the relevant genes could be analyzed. A subset of these showed significant differences in organ specificity and cytokinin response of transcript abundance.

Among the cytokinin-synthesizing IPT genes, IPT5 showed a higher expression in the shoot under all conditions, while IPT7 (and less strongly also IPT9) was consistently more highly expressed in the root (Figure 3a). IPT5 was strongly downregulated in long- 


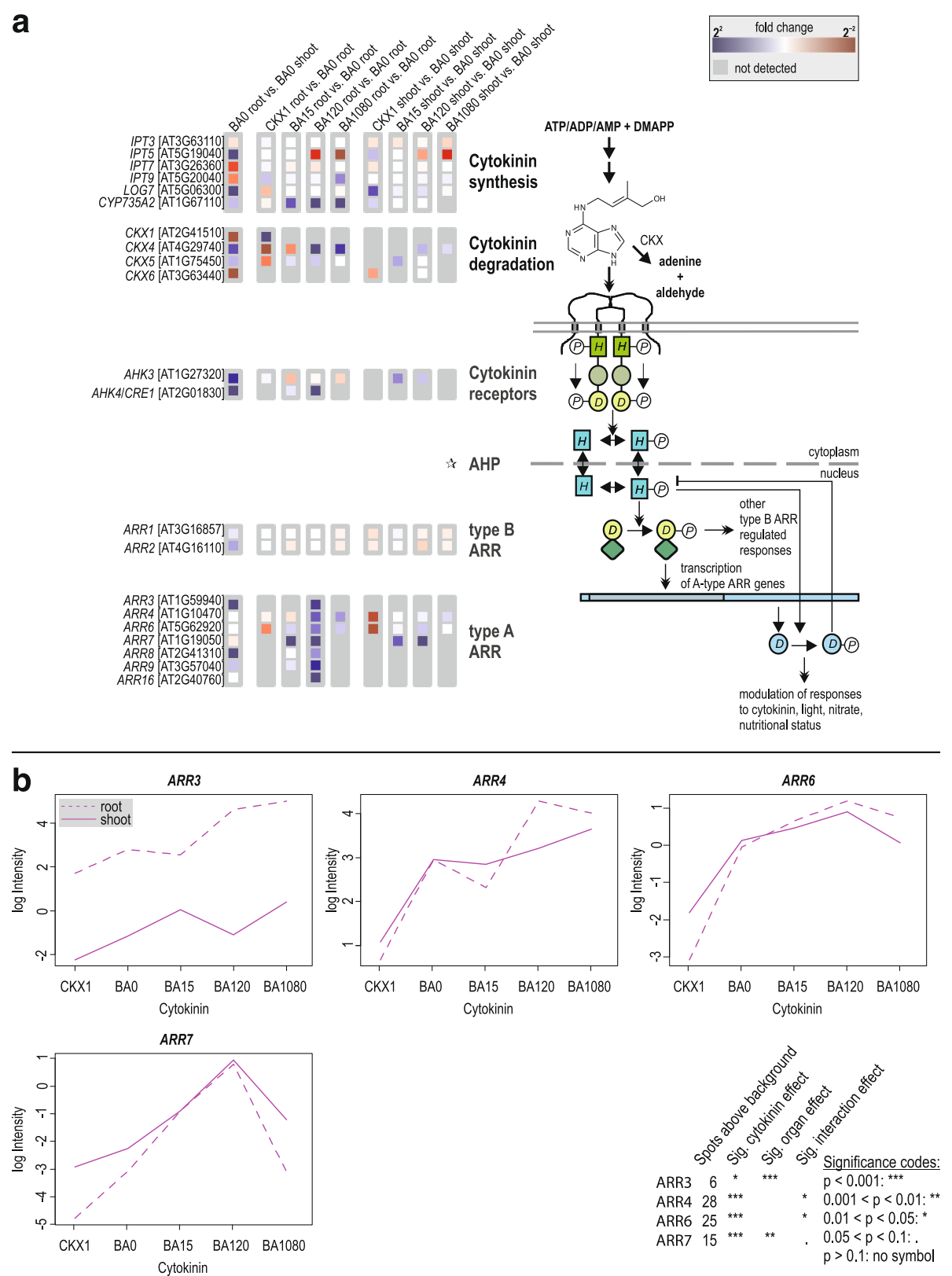

Figure 3 Differential expression of cytokinin signalling and related genes in root and shoot in response to the cytokinin status.

(a) Changes in expression of cytokinin-related genes evaluated with Mapman [157]. Genes associated with functions in cytokinin metabolism or signalling are listed on the left side, and a schematic drawing of cytokinin signal transduction is shown on the right side. Colour coding of the boxes in the middle shows changes of transcript abundance between the samples indicated at the top. Blue indicates an upregulation, red a downregulation. Grey boxes denote genes, which are detected in less than two out of four arrays of the higher expressed condition. Cytokininrelated genes which were never detected or not present on the microarray are not shown. The colour codes were generated using the Mapman software and aligned to a figure using standard image processing software. $\mathbf{s}$ : None of the Arabidopsis histidine phosphotransmitter genes is present on the CATMA V2.3 microarray. (b) Interaction plots and significance of changes of transcript abundance of selected A-type ARR genes. The interaction plots show the relative fluorescence intensity (in log scale) of the spots on the array for the gene indicated on top of each graph in the cytokinin-deficient and cytokinin-treated samples for roots and shoots separately.

term cytokinin-treated roots and upregulated in cytokinin-deficient shoots (see also Figure 3a). In contrast, a strong upregulation in long-term cytokinintreated roots was detected for IPT9, and IPT3 was apparently neither differentially expressed nor regulated by cytokinin. The gene encoding the cytokinin hydroxylase CYP735A2 was strongly upregulated by cytokinin in a root-specific fashion (see below). Among 
the cytokinin-degrading $C K X$ genes, strong differences were found for $C K X 4$ and $C K X 5$, confirming previous data [48]. Both genes were expressed more strongly in the root than in the shoot and both were upregulated by cytokinin and downregulated under conditions of cytokinin deficiency, the response in the root being stronger than in the shoot (Figure 3a). CKX4 has been consistently described as a primary target gene of Btype response regulator ARR1 [49]. In contrast to these two genes, CKX6 was expressed more strongly in the shoot and was hardly regulated by the cytokinin status in our study. Please note that the strong upregulation of CKX1 found in cytokinin-deficient roots results from detection of the transgene. Of the putative cytokinin transporter genes, PUP4 and PUP11 [50] were more strongly expressed in the root and both showed a transient upregulation in the shoot but not in the root in response to cytokinin (Figure 3a).

The known higher expression of the cytokinin receptor gene CRE1/AHK4 in the root [51,52] and its induction by cytokinin [53] was confirmed. The transcript level of the two B-type Arabidopsis response regulator genes $(A R R 1, A R R 2)$ were more strongly expressed in the root and - as expected - not regulated by cytokinin (Figure 3a). In contrast, all known primary cytokinin response genes encoding A-type response regulators (ARR4, ARR6, ARR7, ARR9, and ARR16) detected were equally responsive to cytokinin in both roots and shoots (Figure 3a, Additional file 6: Figure S3a, Additional file 7: Figure S4a, b). Figure $3 \mathrm{~b}$ shows the reduced expression levels of four exemplary A-type $A R R$ genes (ARR3, ARR4, ARR6, and ARR7) in 35S:CKX1 transgenic roots and shoots as compared to the corresponding wild-type tissues and their induction pattern following cytokinin treatment in roots and shoots of the wild type (see also Additional file 6: Figure S3c and Additional file 7:
Figure S4c, d). Despite a generally similar response to an altered cytokinin status, the kinetics and amplitudes of changes in steady state transcript levels differ for the four genes.

Together, these data confirm that the transcript abundance of several cytokinin metabolism and signalling genes depends on the cytokinin status $[6,9,13,15,17]$ indicating regulatory loops between cytokinin metabolism and signalling. The analysis also showed that the reaction patterns are not uniform but complex, with differences in kinetics and organ specificity.

\section{Known and novel genes responding to cytokinin}

In the following sections we will analyse separately the sets of genes that show altered expression patterns following either a treatment of seedlings with cytokinin or under conditions of constitutive cytokinin deficiency (Additional file 2: Table S1 and Additional file 3: Table S2). The organ-specific regulation of some known cytokinin response genes will be addressed and an arbitrary selection of novel cytokinin-regulated genes, which may have escaped previous discovery due to unspecific sampling, is discussed. We will explore similar and differential changes of steady-state transcript levels in both organs, as well as changes that are restricted to either roots or shoots. This organizing principle is followed, although in part genes belonging to a similar context (e.g. related to auxin or brassinosteroid, meristem regulation, nutrient transport, etc.) were categorized into different groups of organ-specific cytokinin-regulation.

\section{Cytokinin-induced changes of transcript abundance}

1,450 of the 8,549 genes (i.e. $\sim 17 \%$ ) that were detected by the arrays were responsive to a short-term or longterm cytokinin treatment (Figure 4). Out of these, 670

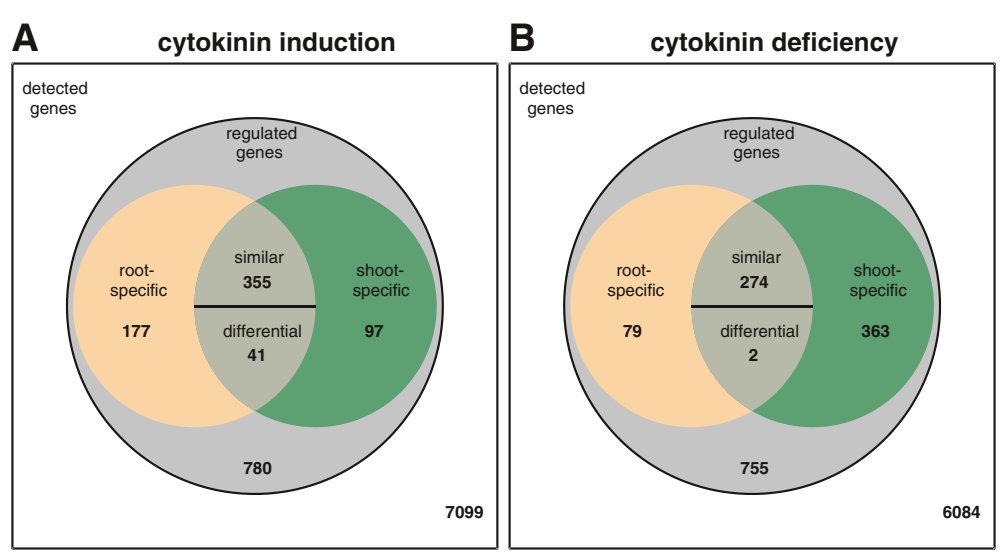

Figure 4 Venn diagrams showing different organ-specific classes of cytokinin-regulated genes. (A) The Venn diagram shows the numbers of detected and regulated genes following $18 \mathrm{~h}$ of cytokinin treatment. (B) The Venn diagram shows the numbers of detected and regulated genes in cytokinin-deficient seedlings. The gene classification was performed as described in Methods and Additional file 6: Figure S3. 
Table 4 Changes of transcript abundance of known cytokinin-regulated genes of Arabidopsis thaliana

\begin{tabular}{|c|c|c|c|c|c|c|c|c|c|c|c|c|c|}
\hline \multirow[t]{3}{*}{ Category } & \multirow[t]{3}{*}{ AGI } & \multirow[t]{3}{*}{ Description } & \multicolumn{8}{|c|}{ Ratio } & \multirow{2}{*}{\multicolumn{2}{|c|}{$\begin{array}{l}\text { Significance } \\
\text { code }\end{array}$}} & \multirow{3}{*}{$\begin{array}{l}\text { Previously } \\
\text { published } \\
\text { in }\end{array}$} \\
\hline & & & \multicolumn{4}{|c|}{ Root } & \multicolumn{4}{|c|}{ Shoot } & & & \\
\hline & & & $\begin{array}{l}\text { CKX1 vs. } \\
\text { BA0 }\end{array}$ & $\begin{array}{l}\text { BA15 vs. } \\
\text { BA0 }\end{array}$ & $\begin{array}{l}\text { BA120 vs. } \\
\text { BA0 }\end{array}$ & $\begin{array}{l}\text { BA1080 vs. } \\
\text { BA0 }\end{array}$ & $\begin{array}{l}\text { CKX1 vs. } \\
\text { BA0 }\end{array}$ & $\begin{array}{l}\text { BA15 vs. } \\
\text { BA0 }\end{array}$ & $\begin{array}{l}\text { BA120 vs. } \\
\text { BA0 }\end{array}$ & $\begin{array}{l}\text { BA1080 vs. } \\
\text { BA0 }\end{array}$ & $\begin{array}{l}\text { Cytokinin } \\
\text { effect }\end{array}$ & $\begin{array}{l}\text { Interaction } \\
\text { effect }\end{array}$ & \\
\hline \multirow[t]{7}{*}{ root-specific } & AT2G40230 & $\begin{array}{l}\text { transferase } \\
\text { family protein }\end{array}$ & 1.07 & 0.81 & 2.72 & 2.99 & 2.32 & 0.93 & 1.18 & 2.13 & $* *$ & $\cdot$ & $A B C E$ \\
\hline & AT1G67110 & $\begin{array}{l}\text { cytochrome P450, } \\
\text { cytokinin hydroxylase } \\
\text { (CYP735A2) }\end{array}$ & 0.61 & 4.20 & 60.65 & 29.72 & 2.09 & 1.05 & 0.90 & 2.06 & $* * *$ & $* * *$ & $A C E F$ \\
\hline & AT2G01830 & $\begin{array}{l}\text { histidine kinase } \\
\text { CRE1/AHK4 }\end{array}$ & 0.64 & 1.39 & 4.14 & 0.77 & 1.60 & 1.38 & 0.83 & 1.92 & & * & $A C F$ \\
\hline & AT4G16990 & $\begin{array}{l}\text { disease resistance } \\
\text { protein TIR-NBS-LRR } \\
\text { class }\end{array}$ & 0.13 & 0.60 & 0.47 & 2.63 & 0.87 & 0.57 & 1.02 & 0.88 & $*$ & $*$ & A F \\
\hline & AT4G19170 & $\begin{array}{l}\text { 9-cis-epoxycarotenoid } \\
\text { dioxygenase }\end{array}$ & 0.93 & 0.3 & 0.18 & 1.08 & 1.55 & 0.68 & 0.59 & 0.64 & $* *$ & & A F \\
\hline & AT1G17190 & glutathione S-transferase & 1.77 & 2.85 & 7.63 & 1.07 & 1.75 & 1.20 & 0.77 & 0.56 & * & * & $C F$ \\
\hline & AT5G47980 & $\begin{array}{l}\text { transferase family } \\
\text { protein }\end{array}$ & 0.35 & 1.61 & 6.18 & 14.36 & 0.82 & 0.47 & 0.56 & 2.00 & $* *$ & * & $C F$ \\
\hline \multirow[t]{4}{*}{ shoot-specific } & AT3G48750 & $\begin{array}{l}\text { A-type cyclin- } \\
\text { dependent kinase }\end{array}$ & 0.95 & 1.00 & 1.40 & 0.65 & 4.01 & 8.78 & 7.92 & 1.84 & . & & $A E$ \\
\hline & AT3G62930 & $\begin{array}{l}\text { glutaredoxin family } \\
\text { protein }\end{array}$ & 1.97 & 2.10 & 2.06 & 2.10 & 0.36 & 0.88 & 1.58 & 2.03 & * & $\cdot$ & $C E$ \\
\hline & AT3G21670 & $\begin{array}{l}\text { nitrate transporter } \\
\text { NTP3 }\end{array}$ & 0.84 & 0.70 & 0.72 & 1.36 & 2.00 & 2.66 & 2.65 & 4.47 & * & & $C F$ \\
\hline & AT5G53290 & $\begin{array}{l}\text { ERF/AP2 subfamily } \\
\text { B-5 member (CRF3) }\end{array}$ & 1.00 & 2.28 & 1.71 & 0.79 & 3.03 & 5.47 & 7.94 & 6.26 & $* * *$ & $* * *$ & $\mathrm{D}$ \\
\hline \multirow[t]{8}{*}{ in both organs } & AT1G69530 & expansin At-EXP1 & 0.89 & 1.52 & 2.18 & 13.23 & 0.93 & 1.00 & 1.27 & 4.16 & *** & & $A B C E$ \\
\hline & AT4G29740 & $\begin{array}{l}\text { cytokinin oxidase } \\
\text { CKX4 }\end{array}$ & 0.09 & 0.43 & 4.30 & 2.88 & 0.83 & 1.20 & 1.90 & 4.44 & $* * *$ & $* *$ & $A C E F$ \\
\hline & AT1G19050 & $\begin{array}{l}\text { A-type response } \\
\text { regulator ARR7 }\end{array}$ & 0.31 & 4.53 & 14.48 & 0.97 & 0.63 & 2.57 & 9.23 & 2.07 & $* * *$ & & $A B F$ \\
\hline & AT2G40670 & $\begin{array}{l}\text { A-type response } \\
\text { regulator ARR16 }\end{array}$ & 0.75 & 2.73 & 12.36 & 1.58 & 2.04 & 0.82 & 4.93 & 5.68 & * & & $A B F$ \\
\hline & AT2G01830 & $\begin{array}{l}\text { histidine kinase } \\
\text { (CRE1/AHK4) }\end{array}$ & 0.64 & 1.39 & 4.14 & 0.77 & 1.60 & 1.38 & 0.83 & 1.92 & & $*$ & $A C F$ \\
\hline & AT1G10470 & $\begin{array}{l}\text { A-type response } \\
\text { regulator ARR4 }\end{array}$ & 0.21 & 0.64 & 2.53 & 2.10 & 0.27 & 0.93 & 1.20 & 1.61 & $* * *$ & & $A B$ \\
\hline & AT2G38750 & annexin & 0.09 & 1.73 & 10.8 & 6.06 & 1.15 & 1.80 & 2.53 & 0.69 & $* * *$ & ${ }^{* *}$ & $A C$ \\
\hline & AT5G64620 & $\begin{array}{l}\text { invertase/pectin } \\
\text { methylesterase }\end{array}$ & 1.54 & 0.67 & 0.71 & 0.38 & 0.11 & 0.37 & 0.30 & 0.47 & $* *$ & $* * *$ & $A C$ \\
\hline
\end{tabular}


Table 4 Changes of transcript abundance of known cytokinin-regulated genes of Arabidopsis thaliana (Continued)

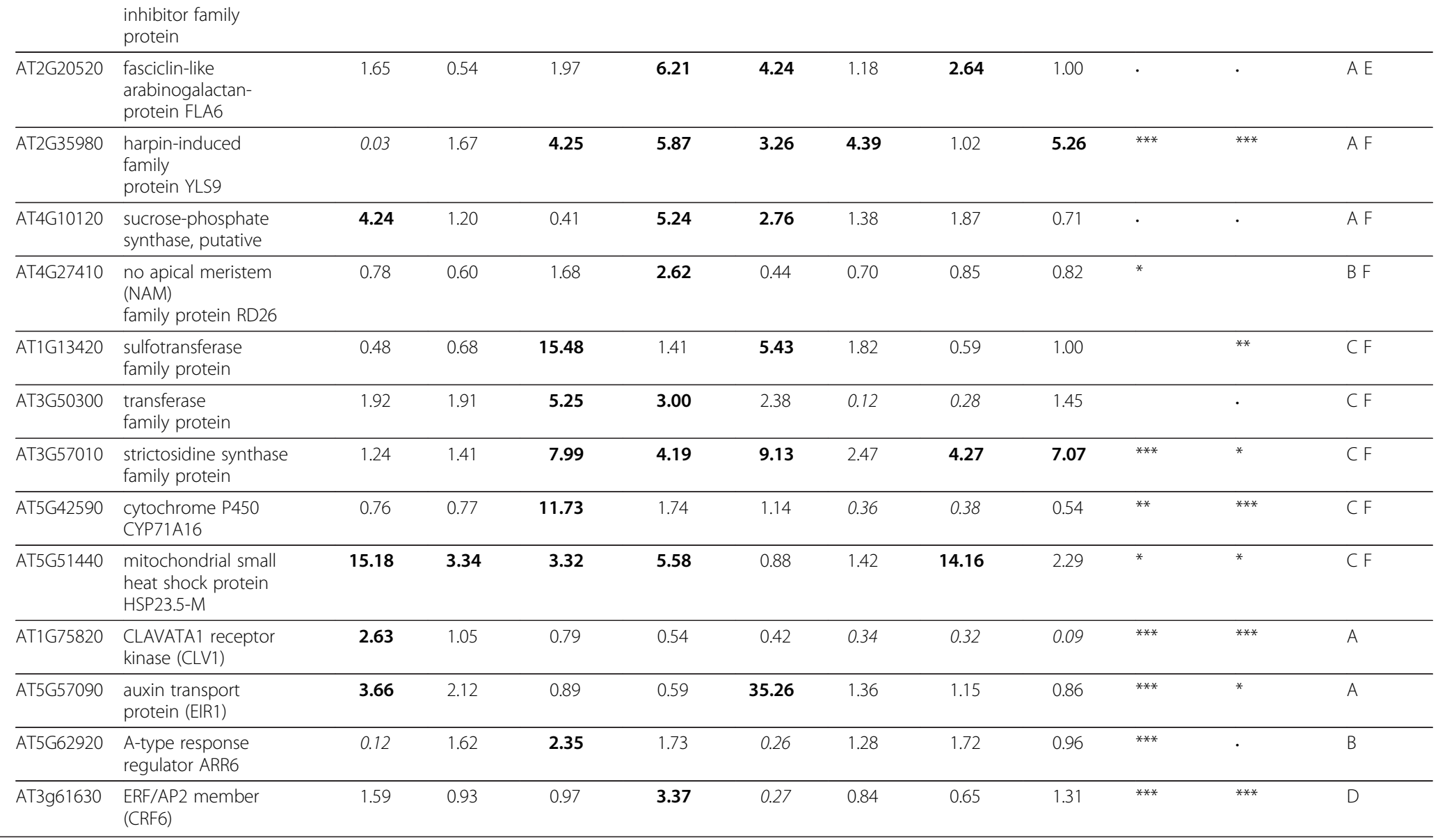

A selection of previously published cytokinin-responsive genes from various publications reporting changes within $24 \mathrm{~h}$ were analyzed for their changes in transcript abundance in response to cytokinin induction or cytokinin deficiency in root and shoot samples. Expression ratios are coded by font-varints as described for Table 1 . Significance codes indicate $\mathrm{p}$-values calculated as described in Methods: $0.1>\cdot>0.05>* 0.01>* *$ $0.001>^{* * *}$. Genes the ( 
genes could be assigned unambiguously to one specific category as follows: the majority, i.e. 396 genes, were regulated in both organs with either a similar or differential expression pattern. The former genes (355) were regulated in both organs in the same direction, while the latter genes (41) were regulated in both organs in the opposite direction. 177 genes were regulated by cytokinin in a root-specific fashion, and 97 genes were regulated in a shoot-specific fashion. A large number of genes (780) were regulated significantly by cytokinin under at least one of the experimental conditions, but lacked a significant organ effect. Most of these genes showed a different steady-state transcript level at only one time point (Additional file 2: Table S1). They were not further analysed, as the focus of this work was on organ specificity. 7099 genes were classified as nonregulated under our conditions (Figure 4 and Additional file 2: Table S1f).

\section{Assignment of organ-specificity to known cytokinin response genes}

Firstly, we examined whether we could assign a root- or shoot-specific response to known cytokinin-regulated genes which had been discovered previously by genome-wide microarray analyses $[6,9,13,15,17]$. In fact, a large number of these genes were detected by the CATMA array and most, but not all, of them were found to be regulated in both organs (Table 4 and Additional file 9: Table S5).

A noteworthy example of a root-specific cytokinin response gene encodes the cytokinin hydroxylase CYP735A2 which responded strongly to cytokinin within minutes. Its transcript level in roots after $120 \mathrm{~min}$ of cytokinin treatment was strongly increased, while it was non-responsive in shoot tissue (Table 4, Additional file 6: Figure S3a). Significantly, the basal level of CYP735A2 expression was similar in both roots and shoots (Additional file 6: Figure S3b, Additional file 7: Figure S4a, b). This regulation is interesting because the hydroxylase catalyzes the conversion of isopentenyl riboside phosphates to trans-zeatin $(t Z)$ riboside phosphates [54], which are inactive precursors of $t Z$-type cytokinins. $t Z$-type cytokinins are the main cytokinins transported in the xylem from roots to shoots $[5,55]$. The exclusive induction of CYP735A2 by cytokinin in roots, which probably results in a locally increased production of $t Z$-type cytokinins, lends support to $t Z$-type cytokinins having a distinct role in rootto-shoot communication [55-57].

An example of a shoot-specific regulated known cytokinin response gene is $C D K A ; 1$, encoding a cyclindependent kinase gene. CDKA;1 is an important cell cycle regulator and is involved in a variety of developmental processes. Because cells expressing more CDKA;1 are more competent for cell division, it is thought to be a prerequisite for post-embryonic cell division $[58,59]$. It was shown recently that the CDK activity level in the shoot apical meristem is important for cellular differentiation [60], a process that is under cytokinin control [30-32]. CDKA;1 regulation in the shoot by cytokinin could be part of the activities orchestrated by cytokinin in the shoot apical meristem.

The organ-specificity of some other known cytokinin response genes is also described in the following sections.

\section{Genes with a similar response in roots and shoots upon cytokinin treatment}

Of the 355 genes displaying a similar cytokinin response in roots and shoots, 133 genes showed an increased transcript level following cytokinin treatment, while the transcript level of 222 genes was reduced (Additional file 2: Table S1). 66 genes showed a rapid change of transcript abundance within $15 \mathrm{~min}$ and thus belong to the immediate-early response genes. The vast majority of the changes became apparent $120 \mathrm{~min}$ or $1080 \mathrm{~min}$ after the treatment. Interestingly, the transcript level of many genes that was increased after 120 min remained increased also after $1080 \mathrm{~min}$. As already mentioned above, it should be noted that there are substantial differences in the basal expression levels of numerous of these genes in roots and shoots which could be of functional relevance as well. An example is the CLV1 gene discussed below, which is approx. 4-fold higher expressed in the untreated wild-type shoots compared to the roots (Additional file 6: Figure S3b, Additional file 7: Figure S4a, b).

Among the upregulated developmental genes, a particularly interesting one encodes the CLAVATA (CLV) formation protein SHEPHERD (SHD, AT4G24190). SHD is a member of the HSP90 protein family and has been suggested to act as a chaperone for the correct folding of nascent CLV1 and/or CLV3-like polypeptides in the endoplasmatic reticulum [61]. Consistently, shd mutant plants are phenotypically reminiscent of $c l v$ mutants. The CLV1 and CLV3 proteins are part of the regulatory loop controlling meristem size and activity in concert with WUSCHEL (WUS) [62]. Cytokinin regulates the expression of CLV1 and WUS, thereby controlling meristematic activity $[30,31,33]$. Transcriptional regulation of the $S H D$ gene possibly represents an additional activity of cytokinin in regulating meristematic activity.

Members of the ERF/AP2 family were noticeably frequent among the cytokinin-responsive transcription factor genes. The transcript levels of eight members of the family (AT5G07580, AT1G77640, AT5G61600, AT1G28370, AT3G15210, AT5G51190, AT5G47220, and AT2G44840) were strongly downregulated by the hormone, but none was upregulated (Table 1, Additional file 6: Figure S3a, Additional file 7: Figure S4a, b). This 
shows that, in addition to the ERF/AP2 subclass of cytokinin-regulated factors (CRF) with its current six members [63], other members of other subclades of the ERF/AP2 family are also cytokinin-regulated (see also below).

Interestingly, numerous ribosomal genes were identified as cytokinin responsive in this study as well as in previous studies $[9,13,63]$. Several developmental processes react sensitively to mutations in ribosomal genes, including embryogenesis, root growth and leaf development, underpinning the functional relevance of the specific assembly of ribosomal proteins in addition to their fundamental role in translation, possibly because they are required to translate specific proteins [64-66]. According to the Gene Ontology database of May 2011, the Arabidopsis genome encodes 474 ribosomal proteins $[67,68]$ and at least 87 transcripts of them responded to cytokinin (Additional file 10: Table S6). The cytokininresponsive ribosomal genes encode proteins of both plastidic and cytoplasmic localisation. Noteworthy, most of the transcripts of nuclear genes encoding plastidic ribosomal proteins reflect the organ shift discussed above, i.e. induction in long-term cytokinin-treated roots and downregulation in cytokinin-deficient shoots. Ribosomal genes encoding cytosolic proteins show diverse cytokinin response patterns. The altered composition of ribosomes and the translational changes that this may cause are a largely unexplored part of the cytokinin response.

The flavonol synthase gene $F L S 1$ was strongly upregulated, particularly in the shoot. FLS1 is part of the flavonol biosynthesis pathway [69] and it is likely that its strong upregulation is part of the induction of anthocyanin accumulation by cytokinin [70]. Cytokinin and flavonoids are involved in regulating several developmental processes: both, for example, are positive regulators of nodule organogenesis [71] but have opposite roles in the control of shoot branching [72-74]. Flavonoids are inhibitors of auxin transport and thus may mediate crosstalk between cytokinin and auxin action. In any case, there are multiple links between cytokinin and flavonoids and effects on the FLS1 transcript level could be part of that. FLS1 was also found among the strongly upregulated genes in cytokinin-deficient plants (see below), illustrating nicely that cytokinin deficiency does not simply induce the opposite changes caused by cytokinin treatment, as already shown by the PCA discussed above.

Five members of the nodulin $M t N 21$ gene family are downregulated by cytokinin: AT2G28120, AT4G08290, AT4G01450, AT4G08300, and AT3G25190 (Additional file 6: Figure S3a, Additional file 7: Figure S4a, b). The role of nodulin MtN21-like genes is not yet understood, but the presence of seven transmembrane domains and structural homologies with bacterial multidrug exporters might suggest a role in a transport function. It was proposed that the maize nodulin MtN21-like gene is probably involved in the transport of a component related to vascular tissue assembly [75], which is interesting in view of the role of cytokinin in vascular development [76].

Several other regulated genes can be associated with known functions of cytokinin, such as crosstalk with other hormones including auxin (e.g. downregulation of IAA7 and IAA13) and gibberellin (downregulation of the gibberellin 2-oxidase gene AT1G02400) or its functions in mineral uptake (e.g. IRT2, ZIP4) (Additional file 2: Table S1).

\section{Root-specific changes in gene expression upon cytokinin treatment}

Among the 177 genes that were regulated only in roots, the strongest differences in expression level were detected for a gene encoding a member of the legume lectin family protein, its transcript abundance increased $>150$-fold (Additional file 2: Table S1). As has been discussed above, the largest specific group of regulated genes encoded plastid proteins, and a particularly interesting gene showing root-specific regulation was cytokinin hydroxylase gene CYP735A2. A root-specific regulation by cytokinin was assigned to two other cytochrome $\mathrm{P} 450$ genes for which cytokinin-regulation has been previously described $[14,15]$. One of them, AT2G34490, encodes the C22 sterol desaturase CYP710A2 involved in brassinosteroid metabolism. It catalyzes the final step in the biosynthesis of brassicasterol and stigmasterol [77,78]. This is interesting as cytokinin and brassinosteroids have been recently shown to act in common pathways in regulating root architecture [79]. The molecular basis for this crosstalk is not known but it is conceivable that regulation of metabolism genes may be part of it. Noticeably, the related gene encoding CYP710A1 and the brassinosteroid biosynthesis gene DIM/DWF are deregulated in cytokinin-deficient plants (see below) indicating that brassinosteroid metabolism is regulated by cytokinin on different levels.

The largest fold-change in transcript abundance between roots of the cytokinin-deficient and long-term cytokinin-treated seedlings was noted for the LBD4 gene, encoding a member of the LOB domain protein family [80] and already noted before in relation to cytokinin [14]. The function of $L B D 4$ is unknown, but members of this plant-specific family of DNA-binding transcription factors are involved in various developmental processes, such as leaf polarity, and floral or inflorescence architecture in different plant species 
[80-84], as well as lateral root formation and the regulation of anthocyanin and nitrogen metabolism [85].

Again, a number of genes were identified that are relevant for auxin action, e.g. encoding the IAA-amido synthase DFL1 (AT5G54510) and PIN4 (AT2G01420), suggesting that cytokinin-auxin crosstalk is realized in many different ways in a tissue-specific fashion. Similarly, genes encoding proteins involved in mineral uptake are also regulated in a root-specific fashion, including iron transporter gene IRT1 as well as phosphate (PHT2;1, AT3G26570) and sulfate transporter genes (Additional file 2: Table S1, Additional file 6: Figure S3a, Additional file 7: Figure S4a, b).

\section{Shoot-specific changes in gene expression upon cytokinin treatment}

97 genes were exclusively regulated in the shoot, of which 23 were upregulated (up to 6-fold), and 74 were downregulated, in both cases most consistently after 120 and $1080 \mathrm{~min}$. One of the most prominent genes that was rapidly and strongly downregulated in the shoot is CLV1 (Table 1, Additional file 6: Figure S3a, Additional file 7: Figure S4a, b). Its negative regulation by cytokinin has been previously reported [30,31,33], but the shootspecific nature of this was not known. Similarly, cytokinin regulation of $C R F 3$, encoding a member of the subfamily B-5 of the ERF/AP2 transcription factor family (AT5G53290), had been shown before [16], but not its shoot-specificity (Table 1). Another member of the ERF/ AP2 transcription factor family (subfamily B-3), ERF5 (AT5G47230), is one of the most strongly downregulated genes in the shoot (Table 1). ERF5 is an activator of GCC box-dependent transcription and is also regulated by ethylene and abiotic stress [86].

The gene encoding the digalactosyldiacylglycerol synthase 1 (DGD1, AT3G11670) was upregulated almost 6-fold by cytokinin treatment. DGD1 catalyzes the synthesis of the galactolipid digalactosyldiacylglycerol (DGDG), requiring monogalactosyldiacylglycerol (MGDG) as a substrate, which is synthesized by mongalactosyldiacylglycerol synthase (MGD) [87,88]. Both galactolipids constitute the predominant and functionally relevant component of thylakoid membranes [89]. Previously, it was shown that the accumulation of MGDG in cucumber seedlings required cytokinin in addition to light, and that both factors play a co-operative role [90]. The response of DGD1 shown here indicates that the cytokinin regulation also comprises this step of galactolipid synthesis, adding another example of the influence of the hormone on chloroplast function.

The serin/threonine protein kinase gene PINOID (PID) [91], encoding a regulator of the auxin response, is downregulated approximately 3 -fold. PID phosphorylates the auxin efflux carrier proteins PIN, thereby changing their apical-basal polar localization and thus increasing basipetal polar auxin transport [92-96]. Although it is not known whether transcriptional regulation of PID plays a role in regulating its kinase activity, it is possible that the downregulation of PID by cytokinin causes an increase in basipetal auxin transport. In any case, in whatever functional context, regulation of PID by cytokinin could be a mechanism in addition to the known regulation of PIN genes $[29,97,98]$ that contributes to the manifold regulatory influences of cytokinin on auxin function.

\section{Genes with differential expression patterns in root and shoot upon cytokinin treatment}

41 genes were upregulated in shoots and downregulated in roots or vice versa. The existence of such a differential organ-specific response pattern could be, for example, achieved by transcription factors that act depending on the cellular or developmental context either as activator or repressor [99]. However, given the low number of genes in this class and the frequently transient nature of their differential regulation, this does not seem to be a general feature of differential cytokinin activity in roots and shoots. Two genes encoding cytochrome P450 enzymes belong in this class and show altered transcript levels at several time points (Additional file 2: Table S1). One of these genes encodes CYP83A1, also called REF2 (AT4G13770), catalyzing the initial conversion of aldoximes to thiohydroximates in the synthesis of glucosinolates not derived from tryptophan. It has also a role in auxin homeostasis [100-102]. F5H2 (AT5G04330) encoding a ferulate 5-hydroxylase involved in lignification [103] is regulated in the opposite way, namely up in the root and down in the shoot. The functional significance of this type of regulation is not known.

\section{Genes differentially expressed under conditions of constitutive cytokinin deficiency}

In cytokinin-deficient tissues of 35S:CKX1 plants, 7,557 genes were detected, of which $1,473(\sim 20 \%)$ showed an altered transcript abundance compared to the wild type. 718 of these genes could be assigned to one specific category. The major effect of cytokinin deficiency was manifested in the shoot, where 639 genes were differently expressed. 363 of these genes were exclusively affected in this organ and 277 were affected in the root as well. A smaller number of 79 genes were regulated only in the root and 2 genes were identified showing differential regulation in root and shoot (Additional file 3: Table S2, Figure 4). One outcome of the analysis was the relatively small overlap of genes affected by cytokinin-deficiency or cytokinin-treatment as described above. There are examples of opposite gene regulation in both conditions, 
e.g. the A-type $A R R$ genes, which are upregulated by cytokinin and downregulated under cytokinin deficiency. Conversely, there are several cases of a change of transcript level in the same direction under both conditions (e.g. FLS1, several AP2/ERF transcription factor genes) illustrating that opposite hormonal conditions may have a similar effect on transcript abundance. The relative shift of the shoot expression pattern towards a more root-like pattern, especially concerning genes encoding plastid proteins, was particularly noteworthy in the light of the effects of long-term cytokinin treatment on the roots described above. In addition, the data show that roots and shoots clearly react with different trancriptomic changes to cytokinin deficiency. Exceptions are general indicators of the cytokinin status, such as the A-type $A R R$ genes, which are lowered in both organs (Figure 3). The alteration of the transcript level of several regulated genes may contribute to the establishment of the cytokinin deficiency syndrome.

\section{Genes with similar reaction in root and shoot under constitutive cytokinin deficiency}

275 genes showed a similar response in roots and shoots: 113 thereof were upregulated and 162 were downregulated (Additional file 3: Table S2). There are several regulated genes that provide insight into the biological functions of cytokinin, such as the strong downregulation of nitrate reductase genes NR1 and NR2 reflecting the functional link between cytokinin and nitrogen usage [104].

A very strongly altered expression level was shown by the sodium transporter gene $H K T 1$, which was upregulated 24-fold in roots and 16-fold in shoots (Additional file 3: Table S2, Additional file 6: Figure S3c, Additional file 7: Figure S4c, d). The main function of HKT1 is the control of $\mathrm{Na}^{+}$entry into plant roots and the root/shoot distribution of $\mathrm{Na}^{+}[105,106]$. Thus, HKT1 has an important role in mediating salt tolerance, as has been shown in ecotypes as well as by forward genetics, and it has been utilized to generate salt-tolerance using a transgenic approach [107-110]. The regulation found here is consistent with the previous finding that $H K T 1 ; 1$ is repressed by cytokinin treatment but showed significantly elevated expression in the B-type response regulator double mutant arr1 arr12 [111]. These data suggested that cytokinin, acting through the transcription factors ARR1 and ARR12, regulates sodium accumulation in the shoots by controlling the expression of HKT1 in the roots. Cytokinin receptors AHK2 and AHK3 were consistently identified as negative regulators of the osmotic stress response and receptor mutants as well as mutants with a reduced cytokinin content were found to be salt resistant $[112,113]$. Another cytokinin-regulated transporter gene was ZIP1
(AT3G12750), which encodes a $\mathrm{Zn}^{2+}$ transporter and was upregulated 3.2- and 4.4-fold in shoots and roots, respectively [114]. Its upregulation by cytokinin deficiency is in accord with the finding that cytokinindeficient plants accumulate higher amounts of $\mathrm{Zn}^{2+}$ in their shoot tissue [26].

Among the transcription factor genes, four ERF/AP2 transcription factor genes (AT1G28370, AT3G16770, AT5G05410, and AT3G15210) are downregulated to about one third of their expression level (Additional file 6: Figure S3c, Additional file 7: Figure S4c, d). Interestingly, three of them are identical to the cytokininregulated AP2/ERFs mentioned above (see Table 1), indicating again that increase and decrease of the cytokinin status may have similar consequences.

MYB12 is another strongly regulated transcription factor gene. MYB12 belongs to subgroup 7 of the R2R3-MYB family and is a flavonol-specific activator of flavonoid biosynthesis [115]. Together with its two other subgroup members, MYB11 and MYB111, it strongly activates the promoters of genes encoding chalcone synthase (CHS), flavanone 3-hydroxylase $(\mathrm{F} 3 \mathrm{H})$, flavonol synthase (FLS1), and - to a lesser extent - chalcone flavanone isomerase $(\mathrm{CHI})$, which are all involved in the formation of flavonols [116]. The upregulation of MYB12 consistently resulted in an enhanced transcript level of CHS (AT5G13930) and FLS1 (Additional file 3: Table S2). We hypothesize that cytokinin-deficient plants contain higher levels of flavonols and/or flavonoids, which have a variety of functions in plant stress defence. Interestingly, auxin and ethylene induce flavonol accumulation through partly identical transcriptional networks [117].

Two well known auxin-related genes, PIN2 and $A X R 1$, were upregulated under cytokinin-deficiency. PIN2 belongs to those genes which show a much higher shoot expression in response to cytokinin deficiency (55-fold increase compared to wild-type shoots) while it is normally predominantly expressed in roots (Table 2 and Additional file 3: Table S2, Additional file 6: Figure S3c, d, Additional file 7: Figure S4, Additional file 6: Figure S3, d). PIN2 encodes a member of the auxin efflux carrier proteins [118-121]. Its regulation by cytokinin has been reported in the context of root meristem size regulation $[97,122]$, but it might also be involved in co-ordinating the activities of cytokinin and auxin in regulating root gravitropism [123]. AXR1, which was upregulated about 5-fold in both organs, encodes part of a dimeric E1 ubiquitin-activating enzyme of the ubiquitin-proteasome protein degradation pathway [124-127] mainly involved in regulating the auxin response, but also other signalling pathways dependent on ubiquitin-dependent protein degradation [128-133]. The upregulation of $A X R 1$ may enhance the potential for neddylation of proteins to be targeted for 
degradation by the proteasome. The Aux/IAA proteins, transcriptional repressors of auxin-inducible genes, are primary targets of this pathway. Higher expression of AXR1 under cytokinin-deficiency suggests an enhanced auxin signalling in cytokinin-deficient plants. The identification of $A X R 1$ as a regulatory target of cytokinin adds another potential regulatory level to cytokininauxin interaction, which, because of the involvement of $A X R 1$ in auxin signalling in many tissues, might be of general relevance for the whole plant.

\section{Root-specifically altered transcript levels under constitutive cytokinin deficiency}

The transcript level of 79 genes was changed in a rootspecific fashion: 35 genes were upregulated and 44 genes were downregulated (Additional file 3: Table S2). The strongest upregulation in roots showed a gene for an amino acid transporter family protein (AT5G65990) which was increased 18-fold (Table 2, Additional file 6: Figure S3a, b, Additional file 7: Figure S4a, b).

The transcript of the CLV3-related gene CLE1 (AT1G73165) was upregulated 5.7-fold under cytokinin deficiency, however, the p-value (0.049) was slightly above our threshold (0.03). There is not much known about the actual function of CLE1. However, CLE1 complemented the clv3 mutant well and also requires CLV1 for signalling, and thus it may be considered a functional homologue [134]. The role of CLV3 and related CLE peptides in the shoot apical meristem has been investigated in great detail [135]. However, they are equally important in root meristem maintenance. Overexpression, as well as the exogenous application of several CLE peptides - including CLV3 - to roots, results in the consumption of root meristematic cells [136-140] and both CLV3 and CLE40, its functional orthologue in roots, promote differentiation in the distal root meristem. CLE40 forms a ligand-receptor pair with ACR4 to regulate WOX5 expression, resulting in a similar regulatory loop for the balance between proliferation and differentiation as the CLV/WUS system in the shoot meristem [141]. It could be that the root-specific upregulation of CLE1 under cytokinin deficiency is functionally relevant for the altered differentiation behaviour of cytokinindeficient roots $[24,26]$.

\section{Shoot-specifically altered transcript levels under constitutive cytokinin deficiency}

363 genes were deregulated in a shoot-specific fashion in 35S:CKX1 transgenic seedlings, which is a more complex response compared to roots. 189 of the genes were upregulated and many showed very strong changes ( $~ 80$-fold) of their expression level and a strong shift towards root-like expression (Additional file 3: Table S2) which has caused the shift of the cytokinin-deficient root sample towards a more root-like position in the PCA analysis discussed above. Interestingly, the three most strongly downregulated genes and two more genes with strongly reduced transcript levels encode AP2/ERF transcription factors (Additional file 3: Table S2, Additional file 6: Figure S3c, Additional file 7: Figure S4c, d), four of which are identical to those downregulated by cytokinin treatment (AT5G51190, AT5G61600, AT2G44840, and AT5G47220) mentioned above.

Several components of the light signalling network, in particular linked to phytochrome A, were found to be deregulated in cytokinin-deficient shoots. SPA1 and COP1 belong to the upregulated genes, while the phyA transcript itself is downregulated to one third of its level in wild-type plants (Additional file 3: Tables S2b and e). PhyA is involved in two light responses: the very-lowfluence response (VLFR) and the far-red-light-dependent high-irradiance response (HIR), the former promoting seed germination with very low quantities of red or farred light and the latter promoting photomorphogenesis [142]. SPA1 (an atypical bHLH transcription factor) and COP1 (an E3 ubiquitin ligase) are negative regulators of partial aspects of both VLFR and HIR. COP1 and SPA1 are able to form a complex which targets PhyA for proteolytic degradation, thereby promoting photomorphogenesis [143]. The upregulation of the COP1 and SPA 1 transcripts by cytokinin may contribute to the rapid degradation of PhyA in its $\mathrm{P}_{f r}$ form and the transcriptional downregulation of PhyA by cytokinin is likely to attenuate PhyA accumulation. Together, the gene regulation is consistent with altered light responses of cytokinin-deficient plants [27] and the known links between cytokinin and light responses [1,2].

Finally, the transcript of the DIM/DWF1 gene encoding an enzyme involved in brassinosteroid biosynthesis [144] was downregulated to one third of its wild-type level in cytokinin-deficient shoots. dim/ dwf1 mutants are brassinosteroid-deficient and show the typical dwarfed phenotype. It would be interesting to study in what way an altered brassinosteroid level is causally involved in establishing the cytokinin deficiency syndrome of which reduced shoot growth is a hallmark [24]. In any case, together with the regulation of $C Y P 710 A$ and $C Y P 710 B$ genes mentioned above our results suggest an influence of cytokinin on brassinosteroid biosynthesis. Reciprocal influences of the two hormones on the expression of their metabolism genes have been observed before; however, the regulation of brassinosteroid metabolism genes by cytokinin was described as being ambiguous and not allowing a clear prediction whether 
this results in an enhanced or decreased brassinosteroid level [145].

\section{Conclusions}

This study reports hitherto unknown differences of transcriptomic changes in root and shoot tissues in response to cytokinin treatment or cytokinin deficiency. One interesting result was the shift of long-term treated wildtype root samples to a more "shoot-like" profile and the opposite shift of cytokinin-deficient shoot samples towards "root-like" expression, both primarily affecting nuclear genes encoding plastid proteins. It would be interesting to analyze whether the whole transcriptome reacts in a rheostat-like fashion to a change in cytokinin status. There are some noteworthy examples of tissuespecific cytokinin responses, the most prominent probably being the cytokinin hydroxylase gene CYP735A2, which is strongly upregulated in root tissue but lacks a response in shoot tissue. This implies that strong negative regulators suppress the cytokinin response of CYP735A2 in shoot tissue. Numerous novel cytokinin response genes were discovered which were missed previously because of unspecific sampling and it can be anticipated that studies with an even higher spatial resolution will continue to discover novel cytokininregulated genes in their functional context [146]. Several novel regulatory influences of cytokinin on metabolism and signalling genes of other hormonal regulators of plant development such as auxin and brassinosteroids were found. Similarly, novel connections between cytokinin and environmental cues operating through transcriptional changes were unravelled supporting the notion that the hormone is involved in regulating a vast array of plant functions [2]. Together these findings generate new hypotheses that need to be tested experimentally in order to fit them into the emerging picture of regulatory transcriptional networks $[145,147]$.

\section{Methods}

Growth, treatment and harvest of Arabidopsis thaliana

Arabidopsis thaliana Col-0 seeds and seeds of ectopic overexpressors of the cytokinin oxidase/dehydrogenase gene $C K X 1$ [24] were surface-sterilized with chlorine gas [148]. Seedlings were grown before treatment for five days in liquid medium (half-strength MS medium, $1 \mathrm{~g} \mathrm{~L}^{-1}$ sucrose, $0.5 \mathrm{gL}^{-1} \mathrm{MES}, \mathrm{pH}$ 5.7) under a $16 \mathrm{~h}$ light $/ 8 \mathrm{~h}$ dark regime at $22^{\circ} \mathrm{C}$. The whole seedlings were then treated with either $5 \mu \mathrm{M}$ 6-benzyladenine (BA) for 15,120 or $1080 \mathrm{~min}$, or for $120 \mathrm{~min}$ in a solvent control, which were both added to the medium. To minimize circadian effects on gene expression, the treatment was timed in such a way that the harvest could be carried out for all samples between $6 \mathrm{~h}$ and $8 \mathrm{~h}$ after the onset of light. To achieve this, both the induction and the harvesting process for each sample covered the whole period of $2 \mathrm{~h}$. At the end of the incubation period, roots and shoots were harvested separately by taking each seedling individually with a soft forceps at the hypocotyl, breaking off the roots of shock-frozen seedlings at the inner wall of a tube swimming in liquid nitrogen and collecting the remaining shoot in another tube. In this way, the breaking point was always very close to the roothypocotyl junction and very pure root and shoot samples were obtained. The roots and shoots of at least 2,400 seedlings were pooled for one sample. Two samples were collected per condition.

RNA extraction, preparation of fluorescently labelled probes, hybridisation of microarrays and generation of raw data was performed as described previously [7]. Each sample was hybridized onto two microarrays, resulting in four microarrays per condition. The CATMA V2.3 microarray [149] of the Microarray Facility of the University Hospital Leuven (MAF, Leuven, Belgium, ArrayExpress accession no. A-MEXP-120) was used for this study. We followed the hybridization strategy used in the European Compendium of Arabidopsis Gene Expression project (http://www.cagecompendium.org), employing a Cy3-labeled mixture of oligonucleotides complementary to the secondary primers for probe amplification as a common reference sample and Cy5 labeling for the biological samples. This allowed for determination of the steady-state mRNA levels as opposed to the ratios usually obtained by two-color microarrays. The raw data are accessible at ArrayExpress (http://www.ebi.ac.uk/arrayexpress/) under the accession E-CAGE-111.

\section{Bioinformatical procedures}

The raw data were normalized and pre-processed using the pre-processing pipeline developed with Bioconductor [150] in R [151] during the course of the CAGE project $[152,153]$. After pre-processing, linear models were fitted for each gene $[154,155]$. Linear modelling was performed using two factors: (1) organ with the levels "root" and "shoot", and (2) cytokinin with the levels "CKX1", "BA0", "BA15", "BA120", and "BA1080". From the individual $p$-values calculated in linear modelling, FDRcorrected $p$-values ("q-values") were calculated [156]. Genes which were above background on less than four arrays were called "not expressed" and excluded from the analysis. Genes with less than ten spots above background exhibited a very high percentage of false positives, so only genes with at least ten spots above background were chosen for further analysis. The resulting dataset of (log) expressions, (log) ratios, 
$p$-values, $q$-values, and spots above background (AbB) was used to generate all further data derived.

Interaction plots were generated in $\mathrm{R}$ and reformatted with standard image editing software (CorelDraw).

Colour-coded expression maps (Figure 2a) were generated using Mapman $[157,158]$. Tables with logratios for the conditions compared were generated in $\mathrm{R}$ for this purpose and exported as tab-delimited text files in a Mapman-compatible format. Genes which were detected on less than two microarrays in the respective more highly expressed condition were flagged as not detected. The Mapman-generated images were exported and the colour-coded boxes were aligned using standard image editing software. Genes were categorized according to their expression patterns by an algorithm shown in Additional file 1: Figure S1a. Two sorting algorithms adapted to the datasets of the cytokinin-induced and the cytokinin-deficient plants, respectively, were implemented in $\mathrm{R}$. This was done by splitting the dataset up into the subsets "root-specific", "shoot-specific", "differential", "similar", "uncategorized", and "not regulated" using an algorithm outlined in Additional file 1: Figure S1.

Principal Component Analysis (PCA) based on the steady-state mRNA levels was carried out using the implementation in TIGR MEV 4 [159] with the standard settings using a restricted dataset of 911 genes with $\geq 10$ spots above background and an FDR-corrected p-value of $\leq 0.0001$. The graphic output was re-formatted using standard image editing software.

GO term enrichment was performed using the Gene Ontology website http://amigo.geneontology.org/ cgi-bin/amigo/term_enrichment [160]. The graphic result was downloaded from the website and adapted to printing format. Normalization of the dataset for the organ effect was carried out using the following formula on the log-transformed expression values for the five shoot samples of each gene:

$$
\begin{aligned}
& \text { norm }_{\text {shoot,condition }}=r a w_{\text {shoot,sondition }}+\left(r \bar{a} w_{\text {root }}-r \bar{a} w_{\text {shoot }}\right) \\
& \text { norm }_{\text {root,condition }}=r a w_{\text {root }, \text { condition }}
\end{aligned}
$$

norm, normalized value; raw, native value; $r \bar{a} w$, average of the native values.

\section{Real-time quantitative PCR analysis}

Gene expression profiles were verified by real-time quantitative PCR analysis using the following protocol. Each reaction contained $1 \times$ reaction buffer $(10 \times$ stock, $160 \mathrm{mM}\left(\mathrm{NH}_{4}\right)_{2} \mathrm{SO}_{4}, 1 \mathrm{M}$ Tris- $\mathrm{HCl}, \mathrm{pH}$ 8.3, $0.1 \%$ Tween-20), $2 \mathrm{mM} \mathrm{MgCl}_{2}, 100 \mu \mathrm{M}$ each dNTP, $0.1 \times$ SYBR Green I (Fluka, St. Louis, MO, USA, 10,000× stock), $50 \mathrm{nM}$ 5-carboxy-X-rhodamine triethylamine salt (ROX, Sigma, St. Louis, MO, USA), $50-300 \mathrm{nM}$ of each primer, $10 \mathrm{mU} / \mu \mathrm{L}$ immolase (BioLine, Luckenwalde, Germany) in a total volume of $20 \mu \mathrm{L}$. Each sample-gene combination was run as triple replicates. Real-time PCR runs were performed in a 7500 Fast system (Applied Biosystems), controlled and evaluated by the 7500 Software V2.0.1 RC. In order to exclude primers binding to unspecific sequences, they were designed using GENOPLANTE ${ }^{\mathrm{m}}$ S.P.A.D.S (http://www. psb.ugent.be/SPADS/) [161] or NCBI Primer-BLAST (http://www.ncbi.nlm.nih.gov/tools/primer-blast/) [162]. The primer sequences are listed in Additional file 11: Table S7.

\section{Additional files}

Additional file 1: Figure S1. Flow chart representing the algorithm to categorize genes detected in this microarray study. Schematic representation of the algorithm used for gene categorization. Only genes, which were detected on at least $25 \%$ of the microarrays were fed into the algorithm.

Additional file 2: Table S1. Gene lists from cytokinin-treated samples. Lists of all genes detected on at least $25 \%$ of the microarrays (i.e. 8 arrays) containing expression data of wild-type samples sorted into the different categories as described in Methods and Additional file 1: Figure S1. The spreadsheet is divided into sections a-f containing genes which are root-specifically (a), shoot-specifically (b), differentially (c), or similarly (d) regulated by cytokinin. Section e contains cytokinin-regulated genes which are not unambiguously classifiable into one of the other categories. Section $f$ contains genes not regulated by cytokinin. CATMA ID, unique identifier of the probe on the CATMA microarray; FDR p-value, $\mathrm{p}$-value corrected for multiple testing; $A G I$, unique gene identifier assigned to Arabidopsis thaliana genes by TAIR. BA0, mock treatment; BA15, 15 min cytokinin treatment; BA120, 2 h cytokinin treatment; BA1080, 18 h cytokinin treatment. The sorting criteria were (a) the sum of all ratios in the root; (b) the sum of all ratios in the shoot; (c) the sum of the absolute value of the log2 of all ratios in root and shoot; (d) the sum of all ratios in root and shoot; (e) the same as for (c); (f) CATMA ID.

Additional file 3: Table S2. Gene lists from cytokinin-deficient samples. Lists of all genes detected on at least $25 \%$ of the microarrays (i.e. 4 arrays) containing expression data of mock-treated wild-type samples (BA0) and samples of cytokinin-deficient plants (CKX1), sorted into the different categories as described in Methods and Additional file 1: Figure S1. The spreadsheet is divided into sections a-f containing genes which are root-specifically (a), shoot-specifically (b), differentially (c), or similarly (d) regulated. Section e contains cytokinin-regulated genes which are not unambiguously classifiable into one of the other categories. Section $f$ contains genes not found regulated by cytokinin. CATMA ID, unique identifier of the probe on the CATMA microarray; FDR p-value, $p$-value corrected for multiple testing; $A G l$, unique gene identifier assigned to Arabidopsis thaliana genes by TAIR. The sorting criteria were (a) the ratio CKX1 vs. Col-0 root; (b) the ratio CKX1 vs. Col-0 shoot; (c) the sum of the absolute value of the log2 of both ratios; (d) the sum of both CKX1 vs. Col-0 ratios; (e) the same as for (c); (f) CATMA ID.

Additional file 4: Table S3. Genes expressed in a more shoot-like fashion in cytokinin-treated roots. (a) List of genes, which are higher expressed in the shoot than in the root and upregulated by $18 \mathrm{~h}$ of cytokinin treatment in the root. (b) List of genes, which are lower expressed in the shoot than in the root and downregulated by $18 \mathrm{~h}$ of cytokinin treatment in the root. FDR-corrected p-values $\leq 0.03$ marked in blue indicate whether a gene is significantly regulated by cytokinin (cytokinin effect), significantly differently expressed roots and shoots (organ effect), or whether its regulation by cytokinin differs significantly between roots and shoots (organ effect). The threshold set for differential expression is 2.5 -fold 
Additional file 5: Figure S2. GO term enrichment for genes indicative of a developmental shift. (a) GO term enrichment of genes which are more shoot-like expressed in cytokinin-induced roots. The figure shows that the only overrepresented class of genes encodes proteins located in the chloroplast. The dataset of Additional file 4: Table 3a was used to generate this figure. Darker boxes indicate a higher significance of overrepresentation of the GO term indicated. (b) GO term enrichment of genes which are more root-like expressed in

cytokinin-deficient shoots. The figure shows that the only overrepresented class of genes encodes proteins located in the chloroplast. The dataset of Additional file 4: Table $3 \mathrm{~b}$ was used to generate this figure using the AmiGO tool (see Methods).

Additional file 6: Figure S3. Expression of selected organ-specific cytokinin-regulated genes mentioned in the text as revealed by microarray analysis and real-time quantitative RT-PCR. (a) Differentially expressed genes after cytokinin induction. (b) Expression ratios of untreated shoots and roots of the genes shown in (a).

(c) Differentially expressed genes under cytokinin deficiency. (d) Expression ratios in wild-type shoots and roots of the genes shown in (c). Cytokinin regulation of selected genes with different organ specificity of the response was tested by microarrays (indicated by diamonds) and qRT-PCR (indicated by bars) using independent biological material. BD, below detection limit of microarray; bd, below detection limit of aRTPCR.

Additional file 7: Figure S4. Expression levels of selected organ-specific cytokinin-regulated genes mentioned in the text as revealed by microarray analysis and real-time quantitative RT-PCR. $(a, b)$ Expression levels of differentially expressed genes after cytokinin treatment. (c, d) Expression levels of differentially expressed genes under cytokinin-deficiency. The expression levels of selected genes with different organ specificity of the response were tested under the conditions indicated in the legend by microarray analysis $(\mathrm{a}, \mathrm{c})$ and qRT-PCR ( $b$, d) using independent biological material. Open diamonds indicate that less than two of the four spots on the microarray were significantly above background. nd, not detected.

Additional file 8: Table S4. Genes expressed in a more root-like fashion in cytokinin-deficient shoots. (a) List of genes, which are higher expressed in the root than in the shoot and upregulated by chronic cytokinin deficiency in the shoot. (b) List of genes, which are lower expressed in the root than in the shoot and downregulated by chronic cytokinin deficiency in the shoot. FDR-corrected p-values $\leq 0.03$ marked in blue indicate whether a gene is significantly regulated by cytokinin (cytokinin effect), significantly differently expressed roots and shoots (organ effect), or whether its regulation by cytokinin differs significantly between roots and shoots (organ effect). The threshold set for differential expression is 2.5-fold.

Additional file 9: Table S5. Root- and shoot-specific changes of transcript abundance of known cytokinin-regulated genes of Arabidopsis thaliana. A selection of previously published cytokinin-responsive genes from various publications were analyzed for their transcriptional regulation in response to cytokinin induction and cytokinin deficiency in root and shoot samples. Expression ratios are colour-coded as described for Table 1. Significance codes indicate p-values calculated as described in Methods: $0.1>\cdot>0.05>* 0.01>$ ${ }^{* *} 0.001>^{* * *}$. Genes that were published in at least two previous publications are listed here. In addition, selected examples of known regulated genes that were only published once were added. A short list of genes can be found in Table 2. The publications are coded by letters: A, Rashotte et al., 2003 [15]; B, Brenner et al., 2005 [9]; C, Kiba et al., 2005 [13]; D, Rashotte et al., 2006 [16]; E, Taniguchi et al., 2007 [17]; F, Argyros et al., 2008 [6]. AGl, unique gene identifier assigned to Arabidopsis thaliana genes by TAIR.

Additional file 10: Table S6. Cytokinin-responsive genes encoding ribosomal proteins. The table shows all cytokinin-regulated genes encoding ribosomal protein according to the $\mathrm{GO}$ localization database. Columns and colour-codes are the same as for Table 2 . The additional column localization shows whether the protein is part of a plastid or cytosolic ribosome, according to the $\mathrm{GO}$ database (http://www.arabidopsis.org/tools/bulk/go/index.jsp).
Additional file 11: Table S7. Primer sequences used for qRT-PCR. The primer sequences were selected using GENOPLANTETMS.P.A.D.S. (http:// www.psb.ugent.be/SPADS/, grey background) or NCBI

Primer-BLAST (http://www.ncbi.nlm.nih.gov/tools/primer-blast/).

\section{Authors' contributions}

WGB carried out all the experimental and bioinformatical work, designed the research and bioinformatic approaches and contributed to the analysis of the data and writing the paper. Both read and approved the final manuscript.

\section{Acknowledgements}

We thank Joke Allemeersch for help and advice in bioinformatics and Camilla Liput and Petra-Michaela Hartmann for performing transcript analyses by real-time PCR. We thank Stefanie Zintl for discussing the links between cytokinin and light. This work was funded by the DFG in the frame of the Arabidopsis Functional Genomics Network (AFGN) and the CAGE project (www.cagecompendium.org, EU project No. QLK3-CT-2002-02035).

Received: 10 August 2011 Accepted: 13 June 2012

Published: 23 July 2012

\section{References}

1. Argueso CT, Ferreira FJ, Kieber JJ: Environmental perception avenues: the interaction of cytokinin and environmental response pathways. Plant Cell Env 2009, 32:1147-1160.

2. Werner T, Schmülling T: Cytokinin action in plant development. Curr Opin Plant Biol 2009, 12:527-538

3. Heyl A, Schmülling T: Cytokinin signal perception and transduction. Curr Opin Plant Biol 2003, 6:480-488.

4. Müller B, Sheen J: Advances in cytokinin signaling. Science 2007, 318:68-69.

5. Sakakibara H: CYTOKININS: Activity, biosynthesis, and translocation. Annu Rev Plant Biol 2006, 57:431-449.

6. Argyros RD, Mathews DE, Chiang Y-H, Palmer CM, Thibault DM, Etheridge N, Argyros DA, Mason MG, Kieber JJ, Schaller GE: Type B response regulators of Arabidopsis play key roles in cytokinin signaling and plant development. Plant Cell 2008, 20:2102-2116.

7. Heyl A, Ramireddy E, Brenner WG, Riefler M, Allemeersch J, Schmülling T: The transcriptional repressor ARR1-SRDX suppresses pleiotropic cytokinin activities in Arabidopsis. Plant Physiol 2008, 147:1380-1395.

8. Ishida K, Yamashino T, Yokoyama A, Mizuno T: Three type-B response regulators, ARR1, ARR10 and ARR12, play essential but redundant roles in cytokinin signal transduction throughout the life cycle of Arabidopsis thaliana. Plant Cell Physiol 2008, 49:47-57.

9. Brenner WG, Romanov GA, Köllmer I, Bürkle L, Schmülling T: Immediate-early and delayed cytokinin response genes of Arabidopsis thaliana identified by genome-wide expression profiling reveal novel cytokinin-sensitive processes and suggest cytokinin action through transcriptional cascades. Plant J 2005 44:314-333.

10. Che P, Gingerich DJ, Lall S, Howell SH: Global and hormone-induced gene expression changes during shoot development in Arabidopsis. Plant Cell 2002, 14:2771-2785.

11. Hoth S, Ikeda Y, Morgante M, Wang X, Zuo J, Hanafey MK, Gaasterland T, Tingey SV, Chua NH: Monitoring genome-wide changes in gene expression in response to endogenous cytokinin reveals targets in Arabidopsis thaliana. FEBS Lett 2003, 554:373-380.

12. Kiba T, Aoki K, Sakakibara H, Mizuno T: Arabidopsis response regulator, ARR22, ectopic expression of which results in phenotypes similar to the wol cytokinin-receptor mutant. Plant Cell Physiol 2004, 45:1063-1077.

13. Kiba T, Naitou T, Koizumi N, Yamashino T, Sakakibara H, Mizuno T: Combinatorial microarray analysis revealing Arabidopsis genes implicated in cytokinin responses through the $\mathrm{His} \rightarrow$ Asp phosphorelay circuitry. Plant Cell Physiol 2005, 46:339-355.

14. Lee DJ, Park JY, Ku SJ, Ha YM, Kim S, Kim MD, Oh MH, Kim J: Genome-wide expression profiling of ARABIDOPSIS RESPONSE REGULATOR 7(ARR7) 
overexpression in cytokinin response. Mol Genet Genomics 2007, 277:115-137.

15. Rashotte AM, Carson SD, To JP, Kieber JJ: Expression profiling of cytokinin action in Arabidopsis. Plant Physiol 2003, 132:1998-2011.

16. Rashotte AM, Mason MG, Hutchison CE, Ferreira FJ, Schaller GE, Kieber JJ: A subset of Arabidopsis AP2 transcription factors mediates cytokinin responses in concert with a two-component pathway. Proc Natl Acad SCi USA 2006, 103:11081-11085.

17. Taniguchi M, Sasaki N, Tsuge T, Aoyama T, Oka A: ARR1 directly activates cytokinin response genes that encode proteins with diverse regulatory functions. Plant Cell Physiol 2007, 48:263-277.

18. Yokoyama A, Yamashino T, Amano Y, Tajima Y, Imamura A, Sakakibara H, Mizuno T: Type-B ARR transcription factors, ARR10 and ARR12, are implicated in cytokinin-mediated regulation of protoxylem differentiation in roots ofArabidopsis thaliana. Plant Cell Physiol 2007, 48:84-96.

19. Brenner WG, Ramireddy E, Heyl A, Schmülling T: Gene regulation by cytokinin. Frontiers in Plant Science 2012, 3:8.

20. Chevalier F, Perazza D, Laporte F, Le Henanff G, Hornitschek P, Bonneville $J M$, Herzog M, Vachon G: GeBP and GeBP-like proteins are noncanonical leucine-zipper transcription factors that regulate cytokinin response in Arabidopsis. Plant Physiol 2008, 146:1142-1154.

21. Köllmer I, Werner T, Schmülling T: Ectopic expression of different cytokinin-regulated transcription factor genes of Arabidopsis thaliana alters plant growth and development. J Plant Physiol 2011, 168:1320-1327.

22. Richter R, Behringer C, Müller IK, Schwechheimer C: The GATA-type transcription factors GNC and GNL/CGA1 repress gibberellin signaling downstream from DELLA proteins and PHYTOCHROME-INTERACTING FACTORS. Genes Dev 2010, 24:2093-2104.

23. Miyawaki K, Matsumoto-Kitano M, Kakimoto T: Expression of cytokinin biosynthetic isopentenyltransferase genes in Arabidopsis: tissue specificity and regulation by auxin, cytokinin, and nitrate. Plant J 2004, 37:128-138.

24. Werner T, Motyka V, Laucou V, Smets R, van Onckelen $H$, Schmülling T: Cytokinin-deficient transgenic Arabidopsis plants show multiple developmental alterations indicating opposite functions of cytokinins in the regulation of shoot and root meristem activity. Plant Cell 2003, 15:2532-2550

25. Werner T, Motyka V, Strnad M, Schmülling T: Regulation of plant growth by cytokinin. Proc Natl Acad Sci U S A 2001, 98:10487-10492.

26. Werner T, Nehnevajova E, Köllmer I, Novak O, Strnad M, Krämer U, Schmülling T: Root-specific reduction of cytokinin causes enhanced root growth, drought tolerance, and leaf mineral enrichment in Arabidopsis and tobacco. Plant Cell 2010, 22:3905-3920.

27. Riefler M, Novak O, Strnad M, Schmülling T: Arabidopsis cytokinin receptor mutants reveal functions in shoot growth, leaf senescence, seed size, germination, root development, and cytokinin metabolism. Plant Cell 2006, 18:40-54.

28. Dello loio R, Linhares FS, Scacchi E, Casamitjana-Martinez E, Heidstra R, Costantino P, Sabatini S: Cytokinins determine Arabidopsis root-meristem size by controlling cell differentiation. Curr Biol 2007, 17:678-682.

29. Dello loio R, Linhares FS, Sabatini S: Emerging role of cytokinin as a regulator of cellular differentiation. Curr Opin Plant Biol 2008, 11:23-27.

30. Bartrina I, Strnad M, Werner T, Schmülling T: Cytokinin regulates the activity of reproductive meristems, flower organ size, ovule formation and thus seed yield in Arabidopsis thaliana. Plant Cell 2011, 23:69-80.

31. Gordon SP, Chickarmane VS, Ohno C, Meyerowitz EM: Multiple feedback loops through cytokinin signaling control stem cell number within the Arabidopsis shoot meristem. Proc Natl Acad Sci U S A 2009, 106:16529-16534.

32. Leibfried A, To JP, Busch W, Stehling S, Kehle A, Demar M, Kieber JJ, Lohmann JU: WUSCHEL controls meristem function by direct regulation of cytokinin-inducible response regulators. Nature 2005, 438:1172-1175.

33. Lindsay DL, Sawhney VK, Bonham-Smith PC: Cytokinin-induced changes inCLAVATA1andWUSCHELexpression temporally coincide with altered floral development inArabidopsis. Plant Sci 2006, 170:1111-1117.
34. Cary AJ, Liu W, Howell SH: Cytokinin action is coupled to ethylene in its effects on the inhibition of root and hypocotyl elongation in Arabidopsis thaliana seedlings. Plant Physiol 1995, 107:1075-1082.

35. Laplaze L, Benkova E, Casimiro I, Maes L, Vanneste S, Swarup R, Weijers D, Calvo V, Parizot B, Herrera-Rodriguez MB, et al: Cytokinins act directly on lateral root founder cells to inhibit root Initiation. Plant Cell 2007, 19:3889-3900.

36. Faiss M, Zalubillová J, Strnad M, Schmülling T: Conditional transgenic expression of the ipt gene indicates a function for cytokinins in paracrine signaling in whole tobacco plants. Plant J 1997, 12:401-415.

37. Skoog F, Miller CO: Chemical regulation of growth and organ formation in plant tissues cultured in vitro. Symp Soc Exp Biol 1957, 54:118-130

38. Werner T, Holst K, Pors Y, Guivarc'h A, Mustroph A, Chriqui D, Grimm B, Schmulling $T$ : Cytokinin deficiency causes distinct changes of sink and source parameters in tobacco shoots and roots. J Exp Bot 2008, 59:2659-2672.

39. Schmid M, Davison TS, Henz SR, Pape UJ, Demar M, Vingron M, Schölkopf B, Weigel D, Lohmann JU: A gene expression map of Arabidopsis thaliana development. Nat Genet 2005, 37:501-506.

40. Loqué $D$, Ludewig U, Yuan L, von Wirén N: Tonoplast intrinsic proteins AtTIP2;1 and AtTIP2;3 facilitate $\mathrm{NH}_{3}$ transport into the vacuole. Plant Physiol 2005, 137:671-680.

41. Parthier B: The role of phytohormones (cytokinin) in chloroplasts development. Biochem Physiol Pfl 1979, 174:173-214.

42. Race $H L$, Herrmann RG, Martin W: Why have organelles retained genomes? Trends Genet 1999, 15:364-370.

43. Che P, Lall S, Nettleton D, Howell SH: Gene expression programs during shoot, root, and callus development in Arabidopsis tissue culture. Plant Physiol 2006, 141:620-637.

44. Cary A, Uttamchandani SJ, Smets R, Van Onckelen HA, Howell SH: Arabidopsis mutants with increased organ regeneration in tissue culture are more competent to respond to hormonal signals. Planta 2001, 213:700-707.

45. Cary AJ, Che P, Howell SH: Developmental events and shoot apical meristem gene expression patterns during shoot development in Arabidopsis thaliana. Plant J 2002, 32:867-877.

46. Atta R, Laurens L, Boucheron-Dubuisson E, Guivarc'h A, Carnero E, Giraudat Pautot V, Rech P, Chriqui D: Pluripotency of Arabidopsis xylem pericycle underlies shoot regeneration from root and hypocotyl explants grown in vitro. Plant J 2009, 57:626-644.

47. Müller B, Sheen J: Cytokinin and auxin interaction in root stem-cell specification during early embryogenesis. Nature 2008, 453:1094-1097.

48. Werner T, Köllmer I, Bartrina I, Holst K, Schmülling T: New insights into the biology of cytokinin degradation. Plant Biol 2006, 8:371-381.

49. Taniguchi M, Kiba T, Sakakibara H, Ueguchi C, Mizuno T, Sugiyama T: Expression of Arabidopsis response regulator homologs is induced by cytokinins and nitrate. FEBS Lett 1998, 429:259-262.

50. Bürkle L, Cedzich A, Döpke C, Stransky H, Okumoto S, Gillissen B, Kühn C, Frommer WB: Transport of cytokinins mediated by purine transporters of the PUP family expressed in phloem, hydathodes, and pollen of Arabidopsis. Plant J 2003, 34:13-26.

51. Higuchi M, Pischke MS, Mähönen AP, Miyawaki K, Hashimoto Y, Seki M, Kobayashi M, Shinozaki K, Kato T, Tabata S, et al: In planta functions of the Arabidopsis cytokinin receptor family. Proc Natl Acad Sci U S A 2004, 101:8821-8826.

52. Ueguchi $\mathrm{C}$, Koizumi H, Suzuki T, Mituno T: Novel family of sensor histidine kinase genes in Arabidopsis thaliana. Plant Cell Physiol 2001, 42:231-235.

53. de León BG-P, Zorrilla JMF, Rubio V, Dahiya P, Paz-Ares J, Leyva A: Interallelic complementation at the Arabidopsis CRE1 locus uncovers independent pathways for the proliferation of vascular initials and canonical cytokinin signalling. Plant J 2004, 38:70-79.

54. Takei K, Yamaya T, Sakakibara H: Arabidopsis CYP735A1andCYP735A2encode cytokinin hydroxylases that catalyze the biosynthesis oftrans-zeatin. J Biol Chem 2004, 279:41866-41872.

55. Hirose N, Takei K, Kuroha T, Kamada-Nobusada T, Hayashi H, Sakakibara H: Regulation of cytokinin biosynthesis, compartmentalization and translocation. J Exp Bot 2008, 59:75-83.

56. Heyl A, Riefler M, Romanov GA, Schmülling T: Properties, functions and evolution of cytokinin receptors. Eur J Cell Biol 2011. doi:10.1016/j. ejcb.2011.1002.1009. in press. 
57. Romanov GA, Lomin SN, Schmülling T: Biochemical characteristics and ligand-binding properties of Arabidopsis cytokinin receptor AHK3 compared to CRE1/AHK4 as revealed by a direct binding assay. J Exp Bot 2006, 57:4051-4058.

58. Adachi S, Nobusawa T, Umeda M: Quantitative and cell type-specific transcriptional regulation of A-type cyclin-dependent kinase in Arabidopsis thaliana. Dev Biol 2009, 329:306-314.

59. Hemerly AS, Ferreira P, de Almeida Engler J, Van Montagu M, Engler G, Inze $\mathrm{D}$ : $c d c 2 a$ expression in Arabidopsis is linked with competence for cell division. Plant Cell 1993, 5:1711-1723.

60. Gaamouche T, Manes C-LO, Kwiatkowska D, Berckmans B, Koumproglou R, Maes S, Beeckman T, Vernoux T, Doonan JH, Traas J, et al: Cyclinan undifferentiated state. Plant J 2010, 64:26-37.

61. Ishiguro S, Watanabe Y, Ito N, Nonaka H, Takeda N, Sakai T, Kanaya H, Okada K: SHEPHERD is the Arabidopsis GRP94 responsible for the formation of functional CLAVATA proteins. EMBO J 2002, 21:898-908.

62. Barton MK: Twenty years on: The inner workings of the shoot apical meristem, a developmental dynamo. Dev Biol 2010, 341:95-113

63. Rashotte A, Goertzen L: The CRF domain defines cytokinin response factor proteins in plants. BMC Plant Biol 2010, 10:74.

64. Byrne ME: A role for the ribosome in development. Trends Plant Sci 2009, 14:512-519.

65. Horiguchi G, Mollá-Morales A, Pérez-Pérez JM, Kojima K, Robles P, Ponce MR, Micol JL, Tsukaya H: Differential contributions of ribosomal protein genes to Arabidopsis thaliana leaf development. Plant J 2011, 65:724-736

66. Weijers D, Franke-van Dijk M, Vencken R-J, Quint A, Hooykaas P, Offringa R: An Arabidopsis Minute-like phenotype caused by a semi-dominant mutation in a RIBOSOMAL PROTEIN S5 gene. Development 2001, 128:4289-4299.

67. Swarbreck D, Wilks C, Lamesch P, Berardini TZ, Garcia-Hernandez M, Foerster H, Li D, Meyer T, Muller R, Ploetz L, et al: The Arabidopsis Information Resource (TAIR): gene structure and function annotation. Nucleic Acids Res 2008, 36:D1009-D1014

68. Gene Ontology Consortium. Creating the gene ontology resource: design and implementation. Genome Res 2001, 11:1425.

69. Prescott AG, Stamford NPJ, Wheeler G, Firmin JL: In vitro properties of a recombinant flavonol synthase from Arabidopsis thaliana. Phytochemistry 2002, 60:589-593.

70. Deikman J, Hammer PE: Induction of anthocyanin accumulation by cytokinins in Arabidopsis thaliana. Plant Physiol 1995, 108:47-57.

71. Frugier F, Kosuta S, Murray JD, Crespi M, Szczyglowski K: Cytokinin: secret agent of symbiosis. Trends Plant Sci 2008, 13:115-120.

72. Böhner S, Gatz C: Characterisation of novel target promoters for the dexamethasone-inducible/tetracycline-repressible regulator TGV using luciferase and isopentenyl transferase as sensitive reporter genes. Mol Gen Genet 2001, 264:860-870

73. Borevitz JO, Xia Y, Blount J, Dixon RA, Lamb C: Activation tagging identifies a conserved MYB regulator of phenylpropanoid biosynthesis. Plant Cell 2000, 12:2383-2394.

74. Tamas |A: Plant hormones and their role in plant growth and development. In Hormonal regulation of apical dominance. Edited by Davies PJ. Dordrecht: Martinus Nijhoff Publishers; 1987:393-410.

75. Guillaumie S, Goffner D, Barbier O, Martinant J-P, Pichon M, Barrière Y. Expression of cell wall related genes in basal and ear internodes of silking brown-midrib-3, caffeic acid O-methyltransferase (COMT) downregulated, and normal maize plants. BMC Plant Biol 2008, 8:71.

76. Bishopp A, Help H, Helariutta Y, Kwang WJ: International Review of Cell and Molecular Biology. Volume 276. In Cytokinin signaling during root development. Edited by Jeon K. San Diego: Academic; 2009:1-48.

77. Morikawa T, Mizutani M, Aoki N, Watanabe B, Saga H, Saito S, Oikawa A, Suzuki H, Sakurai N, Shibata D, et al: Cytochrome P450 CYP710A encodes the sterol C-22 desaturase in Arabidopsis and tomato. Plant Cell 2006, 18:1008-1022.

78. Morikawa T, Mizutani M, Ohta D: Cytochrome P450 subfamily CYP710A genes encode sterol C-22 desaturase in plants. Biochem Soc Trans 2006, 34:1202-1205.

79. Vercruyssen L, Gonzalez N, Werner T, Schmülling T, Inze D: Combining enhanced root and shoot growth reveals cross talk between pathways that control plant organ size in Arabidopsis. Plant Physiol 2011, 155:1339-1352.

80. Shuai B, Reynaga PCG, Springer PS: The LATERAL ORGAN BOUNDARIES gene defines a novel, plant-specific gene family. Plant Physiol 2002, 129:747-761.

81. Husbands A, Bell EM, Shuai B, Smith HMS, Springer PS: LATERAL ORGAN BOUNDARIES defines a new family of DNA-binding transcription factors and can interact with specific bHLH proteins. Nucleic Acids Res 2007, 35:6663-6671.

82. Ueno $Y$, Ishikawa T, Watanabe K, Terakura S, Iwakawa H, Okada K, Machida C, Machida Y: Histone deacetylases and ASYMMETRIC LEAVES2 are involved in the establishment of polarity in leaves of Arabidopsis. Plant Cell 2007, 19:445-457.

83. Bortiri E, Chuck G, Vollbrecht E, Rocheford T, Martienssen R, Hake S: ramosa2 encodes a LATERAL ORGAN BOUNDARY domain protein that determines the fate of stem cells in branch meristems of maize. Plant Cell 2006, 18:574-585.

84. Xu B, Li Z, Zhu Y, Wang H, Ma H, Dong A, Huang $H$ : Arabidopsis genes $A S 1, A S 2$, and JAG negatively regulate boundary-specifying genes to promote sepal and petal development. Plant Physiol 2008 146:566-575.

85. Majer $C$, Hochholdinger F: Defining the boundaries: structure and function of LOB domain proteins. Trends Plant Sci 2011

16:47-52.

86. Fujimoto SY, Ohta M, Usui A, Shinshi H, Ohme-Takagi M: Arabidopsis ethylene-responsive element binding factors act as transcriptional activators or repressors of GCC box-mediated gene expression. Plant Cell 2000, 12:393-404.

87. Härtel H, Lokstein H, Dörmann P, Grimm B, Benning C: Changes in the composition of the photosynthetic apparatus in the galactolipiddeficient dgd1 mutant of Arabidopsis thaliana. Plant Physiol 1997, 115:1175-1184.

88. Reifarth F, Christen G, Seeliger AG, Dörmann P, Benning C, Renger G Modification of the water oxidizing complex in leaves of the dgd mutant of Arabidopsis thaliana deficient in the galactolipid digalactosyldiacylglycerol. Biochemistry 1997, 36:11769-11776.

89. Block MA, Dorne AJ, Joyard J, Douce R: Preparation and characterization of membrane fractions enriched in outer and inner envelope membranes from spinach chloroplasts. II. Biochemical characterization. J Biol Chem 1983, 258:13281-13286

90. Yamaryo Y, Kanai D, Awai K, Shimojima M, Masuda T, Shimada H, Takamiya $\mathrm{K}$-, Ohta $\mathrm{H}$ : Light and cytokinin play a co-operative role in MGDG synthesis in greening cucumber cotyledons. Plant Cell Physiol 2003, 44:844-855

91. Christensen SK, Dagenais N, Chory J, Weigel D: Regulation of auxin response by the protein kinase PINOID. Cell 2000, 100:469-478.

92. Friml J, Yang X, Michniewicz M, Weijers D, Quint A, Tietz O, Benjamins R, Ouwerkerk PBF, Ljung K, Sandberg G, et al: A PINOID-dependent binary switch in apical-basal PIN polar targeting directs auxin efflux. Science 2004, 306:862-865.

93. Huang F, Kemel Zago M, Abas L, van Marion A, Galván-Ampudia CS, Offringa R: Phosphorylation of conserved PIN motifs directs Arabidopsis PIN1 polarity and auxin transport. Plant Cell 2010, 22:1129-1142.

94. Kleine-Vehn J, Huang F, Naramoto S, Zhang J, Michniewicz M, Offringa R, Friml J: PIN auxin efflux carrier polarity is regulated by PINOID kinasemediated recruitment into GNOM-independent trafficking in Arabidopsis. Plant Cell 2009, 21:3839-3849.

95. Michniewicz M, Zago MK, Abas L, Weijers D, Schweighofer A, Meskiene I, Heisler MG, Ohno C, Zhang J, Huang F, et al: Antagonistic regulation of PIN phosphorylation by PP2A and PINOID directs auxin flux. Cell 2007 130:1044-1056.

96. Zhang J, Nodzyński T, Pěnčík A, Rolčík J, Friml J: PIN phosphorylation is sufficient to mediate PIN polarity and direct auxin transport. Proc Nat Acad Sci U S A 2010, 107:918-922

97. Rưžička K, Šimášková M, Duclercq J, Petrášek J, Zažímalová E, Simon S, Friml J, Van Montagu MCE, Benková E: Cytokinin regulates root meristem activity via modulation of the polar auxin transport. Proc Natl Acad Sci U S A 2009, 106:4284-4289.

98. Scacchi E, Salinas P, Gujas B, Santuari L, Krogan N, Ragni L, Berleth T, Hardtke CS: Spatio-temporal sequence of cross-regulatory events in root 
meristem growth. Proc Natl Acad Sci U S A 2010, 107:22734-22739.

99. Ikeda M, Mitsuda N, Ohme-Takagi M: Arabidopsis WUSCHEL is a bifunctional transcription factor that acts as a repressor in stem cell regulation and as an activator in floral patterning. The Plant Cell 2009, 21:3493-3505

100. Bak S, Feyereisen R: The involvement of two P450 enzymes, CYP83B1 and CYP83A1, in auxin homeostasis and glucosinolate biosynthesis. Plant Physiol 2001, 127:108-118.

101. Hemm MR, Ruegger MO, Chapple C: The Arabidopsis ref2 mutant is defective in the gene encoding CYP83A1 and shows both phenylpropanoid and glucosinolate phenotypes. Plant Cell 2003, 15:179-194.

102. Naur $P$, Petersen BL, Mikkelsen MD, Bak S, Rasmussen H, Olsen CE, Halkier BA: CYP83A1 and CYP83B1, two nonredundant cytochrome P450 enzymes metabolizing oximes in the biosynthesis of glucosinolates in Arabidopsis. Plant Physiol 2003, 133:63-72.

103. Raes J, Rohde A, Christensen JH, Van de Peer Y, Boerjan W: Genome-wide characterization of the lignification toolbox in Arabidopsis. Plant Physiol 2003, 133:1051-1071

104. Kiba T, Kudo T, Kojima M, Sakakibara H: Hormonal control of nitrogen acquisition: roles of auxin, abscisic acid, and cytokinin. J Exp Bot 2011, 62:1399-1409.

105. Rus A, Yokoi S, Sharkhuu A, Reddy M, B-h L, Matsumoto TK, Koiwa H, Zhu J-K, Bressan RA, Hasegawa PM: AtHKT1 is a salt tolerance determinant that controls $\mathrm{Na}^{+}$entry into plant roots. Proc Natl Acad Sci U S A 2001, 98:14150-14155.

106. Mäser $P$, Eckelman $B$, Vaidyanathan $R$, Horie $T$, Fairbairn DJ, Kubo M, Yamagami M, Yamaguchi K, Nishimura M, Uozumi N, et al: Altered shoot/ root $\mathrm{Na}^{+}$distribution and bifurcating salt sensitivity inArabidopsisby genetic disruption of the $\mathrm{Na}^{+}$transporterAtHKT1. FEBS Lett 2002, 531:157-161.

107. Jha D, Shirley N, Tester M, Roy SJ: Variation in salinity tolerance and shoot sodium accumulation in Arabidopsis ecotypes linked to differences in the natural expression levels of transporters involved in sodium transport. Plant Cell Env 2010, 33:793-804.

108. Koiwa H, Bressan RA, Hasegawa PM: Identification of plant stress-responsive determinants in Arabidopsis by large-scale forward genetic screens. J Exp Bot 2006, 57:1119-1128.

109. Møller IS, Gilliham M, Jha D, Mayo GM, Roy SJ, Coates JC, Haseloff J, Tester $\mathrm{M}$ : Shoot $\mathrm{Na}^{+}$exclusion and increased salinity tolerance engineered by cell type-specific alteration of $\mathrm{Na}^{+}$transport in Arabidopsis. Plant Cell 2009, 21:2163-2178

110. Rus A, Baxter I, Muthukumar B, Gustin J, Lahner B, Yakubova E, Salt DE: Natural variants of AtHKT1 enhance $\mathrm{Na}^{+}$accumulation in two wild populations of Arabidopsis. PLoS Genet 2006, 2:e210.

111. Mason MG, Jha D, Salt DE, Tester M, Hill K, Kieber JJ, Eric Schaller G: Type-B response regulators $A R R 1$ and $A R R 12$ regulate expression of $A t H K T 1 ; 1$ and accumulation of sodium in Arabidopsis shoots. Plant J 2010, 64:753-763.

112. Nishiyama R, Watanabe $Y$, Fujita $Y$, Le DT, Kojima M, Werner T, Vankova $R$, Yamaguchi-Shinozaki K, Shinozaki K, Kakimoto $T$, et al: Analysis of cytokinin mutants and regulation of cytokinin metabolic genes reveals important regulatory roles of cytokinins in drought, salt and abscisic acid responses, and abscisic acid biosynthesis. The Plant Cell 2011, 23:2169-2183.

113. Tran L-SP, Urao T, Qin F, Maruyama K, Kakimoto T, Shinozaki K, YamaguchiShinozaki K: Functional analysis of AHK1/ATHK1 and cytokinin receptor histidine kinases in response to abscisic acid, drought, and salt stress in Arabidopsis. Proc Natl Acad Sci U S A 2007, 104:20623-20628.

114. Grotz N, Fox T, Connolly E, Park W, Guerinot ML, Eide D: Identification of a family of zinc transporter genes from Arabidopsis that respond to zinc deficiency. Proc Natl Acad Sci U S A 1998, 95:7220-7224.

115. Mehrtens F, Kranz H, Bednarek P, Weisshaar B: The Arabidopsis transcription factor MYB12 is a flavonol-specific regulator of phenylpropanoid biosynthesis. Plant Physiol 2005, 138:1083-1096.

116. Stracke R, Ishihara H, Huep G, Barsch A, Mehrtens F, Niehaus K, Weisshaar B: Differential regulation of closely related R2R3-MYB transcription factors controls flavonol accumulation in different parts of the Arabidopsis thaliana seedling. Plant J 2007, 50:660-677.
117. Lewis DR, Ramirez MV, Miller ND, Vallabhaneni P, Ray WK, Helm RF, Winkel BSJ, Muday GK: Auxin and ethylene induce flavonol accumulation through distinct transcriptional networks. Plant Physiol 2011, 156:144-164.

118. Chen R, Hilson P, Sedbrook J, Rosen E, Caspar T, Masson PH: The Arabidopsis thaliana AGRAVITROPIC 1 gene encodes a component of the polar-auxintransport efflux carrier. Proc Natl Acad Sci U S A 1998, 95:15112-15117.

119. Luschnig C, Gaxiola RA, Grisafi P, Fink GR: EIR1, a root-specific protein involved in auxin transport, is required for gravitropism in Arabidopsis thaliana. Genes Dev 1998, 12:2175-2187.

120. Müller A, Guan C, Gälweiler L, Tänzler P, Huijser P, Marchant A, Parry G, Bennett M, Wisman E, Palme K: AtPIN2 defines a locus of Arabidopsis for root gravitropism control. EMBO J 1998, 17:6903-6911.

121. Utsuno K, Shikanai T, Yamada Y, Hashimoto T: AGR, an Agravitropic locus of Arabidopsis thaliana, encodes a novel membrane-protein family member. Plant Cell Physiol 1998, 39:1111-1118.

122. Dello loio R, Nakamura K, Moubayidin L, Perilli S, Taniguchi M, Morita MT, Aoyama T, Costantino P, Sabatini S: A genetic framework for the control of cell division and differentiation in the root meristem. Science 2008, 322:1380-1384.

123. Aloni R, Aloni E, Langhans M, Ullrich Cl: Role of cytokinin and auxin in shaping root architecture: regulating vascular differentiation, lateral root initiation, root apical dominance and root gravitropism. Ann Bot 2006, 97:883-893.

124. del Pozo JC, Estelle M: The Arabidopsis cullin AtCUL1 is modified by the ubiquitin-related protein RUB1. Proc Natl Acad Sci U S A 1999, 96:15342-15347

125. del Pozo JC, Timpte C, Tan S, Callis J, Estelle M: The ubiquitin-related protein RUB1 and auxin response in Arabidopsis. Science 1998, 280:1760-1763.

126. Leyser HMO, Lincoln CA, Timpte C, Lammer D, Turner J, Estelle M: Arabidopsis auxin-resistance gene AXR1 encodes a protein related to ubiquitin-activating enzyme E1. Nature 1993, 364:161-164.

127. Timpte C, Lincoln C, Pickett FB, Turner J, Estelle M: TheAXR1andAUX1genes ofArabidopsisfunction in separate auxin-response pathways. Plant J 1995, 8:561-569.

128. Estelle M, Klee HJ: Arabidopsis. In Auxin and Cytokinin. New York: Cold Spring Harbor Laboratory Press; 1994.

129. Ruegger M, Dewey E, Gray WM, Hobbie L, Turner J, Estelle M: The TIR1 protein of Arabidopsis functions in auxin response and is related to human SKP2 and yeast Grr1p. Genes Dev 1998, 12:198-207.

130. Schwechheimer C, Serino G, Deng X-W: Multiple ubiquitin ligase-mediated processes require COP9 signalosome and AXR1 function. Plant Cell 2002, 14:2553-2563

131. Tiryaki I, Staswick PE: An Arabidopsis mutant defective in jasmonate response is allelic to the auxin-signaling mutant axr1. Plant Physiol 2002, 130:887-894.

132. Xu L, Liu F, Lechner E, Genschik P, Crosby WL, Ma H, Peng W, Huang D, Xie $\mathrm{D}$ : The $\mathrm{SCF}^{\mathrm{CO} 11}$ ubiquitin-ligase complexes are required for jasmonate response in Arabidopsis. Plant Cell 2002, 14:1919-1935.

133. Nakamura A, Shimada Y, Goda H, Fujiwara MT, Asami T, Yoshida S: AXR1 is involved in BR-mediated elongation and SAUR-AC1 gene expression in Arabidopsis. FEBS Lett 2003, 553:28-32.

134. Ni J, Clark SE: Evidence for functional conservation, sufficiency, and proteolytic processing of the CLAVATA3 CLE domain. Plant Physiol 2006 140:726-733.

135. Wang G, Fiers M: CLE peptide signaling during plant development. Protoplasma 2010, 240:33-43

136. Casamitjana-Martínez E, Hofhuis HF, Xu J, Liu C-M, Heidstra R, Scheres B: Root-specific CLE19 overexpression and the sol1/2 suppressors implicate a CLV-like pathway in the control of Arabidopsis root meristem maintenance. Curr Biol 2003, 13:1435-1441.

137. Fiers M, Golemiec E, Xu J, van der Geest L, Heidstra R, Stiekema W, Liu C-M: The 14-amino acid CLV3, CLE19, and CLE40 peptides trigger consumption of the root meristem in Arabidopsis through a CLAVATA2-dependent pathway. Plant Cell 2005, 17:2542-2553.

138. Fiers M, Hause G, Boutilier K, Casamitjana-Martínez E, Weijers D, Offringa R, van der Geest L, van Lookeren Campagne M, Liu C-M: Mis-expression of the CLV3/ESR-like gene CLE19 in Arabidopsis leads to a consumption of root meristem. Gene 2004, 327:37-49. 
139. Hobe M, Müller R, Grünewald M, Brand U, Simon R: Loss of CLE40, a protein functionally equivalent to the stem cell restricting signal CLV3, enhances root waving in Arabidopsis. Dev Genes Evol 2003, 213:371.

140. Strabala TJ, O'Donnell PJ, Smit A-M, Ampomah-Dwamena C, Martin EJ, Netzler N, Nieuwenhuizen NJ, Quinn BD, Foote HCC, Hudson KR: Gain-of-function phenotypes of many CLAVATA3/ESR genes, including four new family members, correlate with tandem variations in the conserved CLAVATA3/ESR domain. Plant Physiol 2006, 140:1331-1344.

141. Stahl Y, Wink RH, Ingram GC, Simon R: A signaling module controlling the stem cell niche in Arabidopsis root meristems. Curr Biol 2009, 19:909-914

142. Wang $H$, Deng XW: Dissecting the phytochrome A-dependent signaling network in higher plants. Trends Plant Sci 2003, 8:172-178.

143. Saijo Y, Zhu D, Li J, Rubio V, Zhou Z, Shen Y, Hoecker U, Wang H, Deng XW: Arabidopsis COP1/SPA1 complex and FHY1/FHY3 associate with distinct phosphorylated forms of phytochrome $A$ in balancing light signaling. Mol Cell 2008, 31:607-613.

144. Klahre U, Noguchi T, Fujioka S, Takatsuto S, Yokota T, Nomura T, Yoshida S, Chua N-H: The Arabidopsis DIMINUTO/DWARF1 gene encodes a protein involved in steroid synthesis. Plant Cell 1998, 10:1677-1690.

145. Nemhauser JL, Hong F, Chory J: Different plant hormones regulate similar processes through largely nonoverlapping transcriptional responses. Cell 2006, 126:467-475.

146. Zhao Z, Andersen SU, Ljung K, Doležal K, Miotk A, Schultheiss SJ, Lohmann $J U$ : Hormonal control of the shoot stem-cell niche. Nature 2010, 465:1089-1092.

147. Petricka JJ, Benfey PN: Reconstructing regulatory network transitions. Trends Cell Biol 2011, 21:442-451.

148. Clough SJ, Bent AF: Floral dip: a simplified method for Agrobacteriummediated transformation of Arabidopsis thaliana. Plant J 1998, 16:735-743

149. Hilson P, Allemeersch J, Altmann T, Aubourg S, Avon A, Beynon J, Bhalerao RP, Bitton F, Caboche M, Cannoot B, et al: Versatile gene-specific sequence tags for Arabidopsis functional genomics: transcript profiling and reverse genetics applications. Genome Res 2004, 14:2176-2189

150. Gentleman RC, Carey VJ, Bates DM, Bolstad B, Dettling M, Dudoit S, Ellis B, Gautier L, Ge Y, Gentry J, et al: Bioconductor: open software development for computational biology and bioinformatics. Genome Biol 2004, 5:R80.

151. R Development Core Team: $R$ : A language and environment for statistical computing. Vienna, Austria: R Foundation for statistical computing; 2006. ISBN 3-900051-07-0, http://www.R-project.org.

152. Hilson P, Small I, Kuiper MT: European consortia building integrated resources for Arabidopsis functional genomics. Curr Opin Plant Biol 2003, 6:426-429.

153. Allemeersch J: Statistical analysis of microarray data: applications in platform comparison, compendium data, and array CGH. Katholieke Universiteit Leuven, Electrical engineering: Doctoraat; 2006.

154. Kerr MK, Martin M, Churchill GA: Analysis of variance for gene expression microarray data. J Comput Biol 2000, 7:819-837.

155. Wolfinger RD, Gibson G, Wolfinger ED, Bennett L, Hamadeh H, Bushel P, Afshari C, Paules RS: Assessing gene significance from CDNA microarray expression data via mixed models. J Comput Biol 2001, 8:625-637.

156. Benjamini $Y$, Hochberg $Y$ : Controlling the false discovery rate - a practical and powerful approach to multiple testing. J R Stat Soc B Methods 1995, 9:289-300.

157. Thimm O, Blaesing O, Gibon Y, Nagel A, Meyer S, Krueger P, Selbig J, Mueller LA, Rhee SY, Stitt M: MAPMAN: a user-driven tool to display genomics data sets onto diagrams of metabolic pathways and other biological processes. Plant J 2004, 37:914-939.

158. Usadel B, Nagel A, Thimm O, Redestig H, Blaesing OE, Palacios-Rojas N, Selbig J, Hannemann J, Piques MC, Steinhauser D, et al: Extension of the visualization tool MapMan to allow statistical analysis of arrays, display of coresponding genes, and comparison with known responses. Plant Physiol 2005, 138:1195-1204.

159. Pavlidis $P$, Noble WS: Analysis of strain and regional variation in gene expression in mouse brain. Genome Biol 2001, 2:research0042research0042.15.

160. Carbon S, Ireland A, Mungall CJ, Shu S, Marshall B, Lewis S, Hub A, Group WPW: AmiGO: online access to ontology and annotation data. Bioinformatics 2009, 25:288-289.
161. Thareau V, Dehais $P$, Serizet $C$, Hilson P, Rouze P, Aubourg S: Automatic design of gene-specific sequence tags for genome-wide functional studies. Bioinformatics 2003, 19:2191-2198.

162. Rozen S, Skaletsky HJ: Bioinformatics Methods and Protocols: Methods in Molecular Biology. In Primer3 on the WWW for general users and for biologist programmers. Edited by Krawetz S, Misener S. Totowa, NJ: Humana Press; 2000:365-386.

doi:10.1186/1471-2229-12-112

Cite this article as: Brenner and Schmülling: Transcript profiling of cytokinin action in Arabidopsis roots and shoots discovers largely similar but also organ-specific responses. BMC Plant Biology 2012 12:112.

\section{Submit your next manuscript to BioMed Central and take full advantage of:}

- Convenient online submission

- Thorough peer review

- No space constraints or color figure charges

- Immediate publication on acceptance

- Inclusion in PubMed, CAS, Scopus and Google Scholar

- Research which is freely available for redistribution

Submit your manuscript at www.biomedcentral.com/submit
C BioMed Central 